\title{
New insights into the effect of pressure on catalytic hydropyrolysis of biomass
}

Stummann, Magnus Zingler; Høj, Martin; Hansen, Asger Baltzer; Davidsen, Bente; Wiwel, Peter; Gabrielsen, Jostein; Jensen, Peter Arendt; Jensen, Anker Degn

\section{Published in:}

Fuel Processing Technology

Link to article, DOI:

10.1016/j.fuproc.2019.05.037

Publication date:

2019

Document Version

Peer reviewed version

Link back to DTU Orbit

Citation (APA):

Stummann, M. Z., Høj, M., Hansen, A. B., Davidsen, B., Wiwel, P., Gabrielsen, J., Jensen, P. A., \& Jensen, A. D. (2019). New insights into the effect of pressure on catalytic hydropyrolysis of biomass. Fuel Processing Technology, 193, 392-403. https://doi.org/10.1016/j.fuproc.2019.05.037

\section{General rights}

Copyright and moral rights for the publications made accessible in the public portal are retained by the authors and/or other copyright owners and it is a condition of accessing publications that users recognise and abide by the legal requirements associated with these rights.

- Users may download and print one copy of any publication from the public portal for the purpose of private study or research.

- You may not further distribute the material or use it for any profit-making activity or commercial gain

- You may freely distribute the URL identifying the publication in the public portal 


\section{New insights into the effect of pressure on 2 catalytic hydropyrolysis of biomass}

Magnus Zingler Stummann ${ }^{\mathrm{a}}$, Martin $\mathrm{H} \varnothing \mathrm{j}^{\mathrm{a}}$, Asger Baltzer Hansen ${ }^{\mathrm{b}}$, Bente Davidsen ${ }^{\mathrm{b}}$, Peter Wiwel ${ }^{\mathrm{b}}$, Jostein Gabrielsen $^{\mathrm{b}}$, Peter Arendt Jensen ${ }^{\mathrm{a}}$, Anker Degn Jensen ${ }^{\mathrm{a}}$

${ }^{a}$ Department of Chemical and Biochemical Engineering, Technical University of Denmark (DTU), 2800 Kgs. Lyngby (Denmark)

${ }^{b}$ Haldor Topsøe A/S, 2800 Kgs. Lyngby (Denmark)

$\underline{* a j @ k t . d t u . d k}$

\section{Abstract}

Catalytic hydropyrolysis of beech wood has been conducted in a fluid bed reactor at $450{ }^{\circ} \mathrm{C}$ with a sulfided CoMo catalyst followed by a fixed bed hydrodeoxygenation (HDO) reactor with a sulfided NiMo catalyst at hydrogen pressures between 3.0 and 35.8 bar. Using both reactors the condensable organic yield (condensed organic and $\mathrm{C}_{4+}$ in gas) varied between 18.7 and $21.5 \mathrm{wt.} \%$ dry ash free basis (daf) and was independent of the hydrogen pressure. At 15.9 bar hydrogen or higher the condensed organic phase was essentially oxygen free $(<0.01$ wt.\% dry basis $(\mathrm{db}))$, but decreasing the hydrogen pressure to 3.0 bar increased the oxygen content to $7.8 \mathrm{wt} . \% \mathrm{db}$. The char and coke yield was close to constant (11.0-12.7 wt.\% daf) at hydrogen pressures between 15.9 and 35.8 bar, but increased to 15.7 wt.\% at 3.0 bar hydrogen due to an increase in the polymerization of pyrolysis vapors. The measured carbon content on the spent catalysts from both the fluid bed and HDO reactor showed that coking of the catalysts increased when the hydrogen pressure was decreased below 15.9 bar. The increased coking at low hydrogen pressure $(<15.9$ bar) was ascribed to the polymerization of the more reactive oxygenates produced in the fluid bed reactor.

\section{Keywords}

- Catalytic hydropyrolysis 
- Deactivation

25

- Biofuel

26 - Low pressure

27

- Hydrodeoxygenation

28

- Oil characterization

29 


\section{Abbreviations}

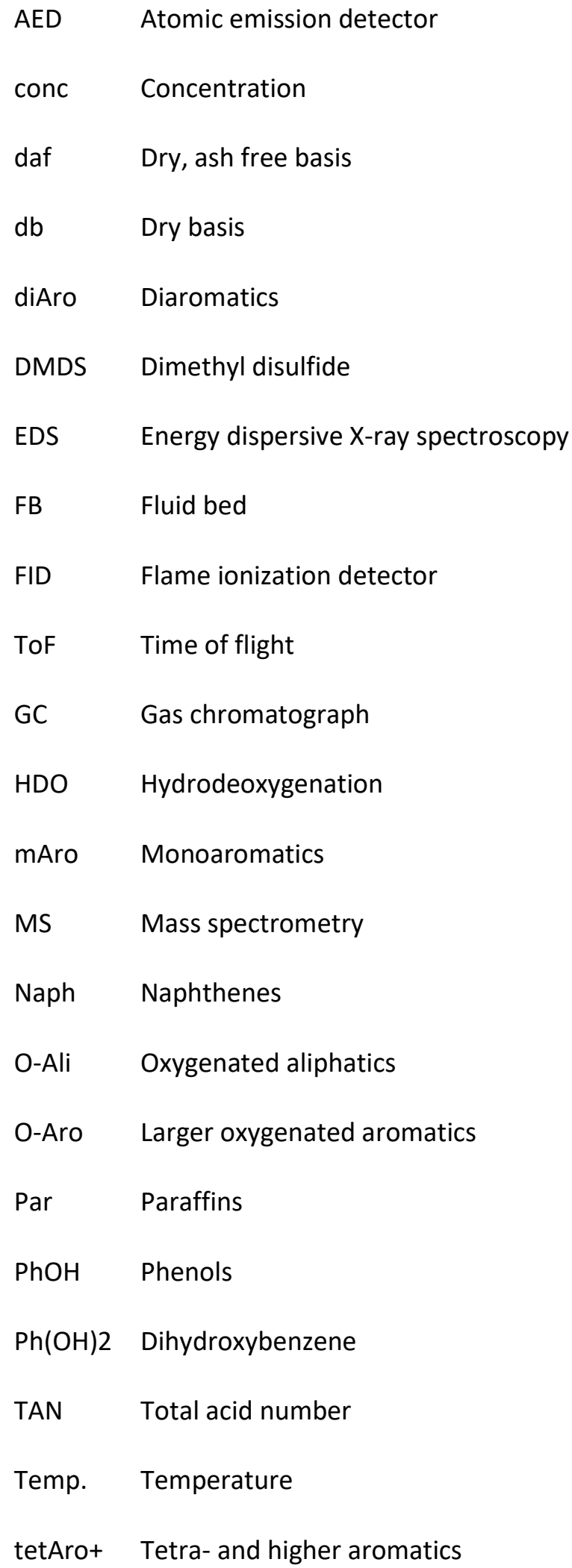


triAro

Triaromatics

31 


\section{Introduction}

Recent research have shown that catalytic hydropyrolysis of biomass is an efficient method for production of renewable liquid fuels with a low carbon footprint [1-4]. In this process pyrolysis takes place in a hydrogen atmosphere and a catalyst is used as heat carrier. This enables the hydrogenation of the oxygenates as soon as they are formed by the pyrolysis process, thus decreasing the extent of polymerization reactions [5]. Since catalytic hydropyrolysis is exothermic, as opposed to inert pyrolysis, additional heat to the fluid bed reactor is not required.

In GTI's process called $\mathrm{IH}^{2}$ catalytic hydropyrolysis takes place in a fluid bed reactor at temperatures between $336-469^{\circ} \mathrm{C}$ and the produced vapors are sent to a fixed bed hydrodeoxygenation (HDO) reactor operated at $343-399^{\circ} \mathrm{C}$ and the total pressure is between 19.5 and 24.1 bar [1,2]. Using maple and pine wood the $\mathrm{IH}^{2}$ process has been running continuously for 750 hours with a feeding rate of $50 \mathrm{~kg} / \mathrm{h}$ at a hydrogen pressure of 24 bar with a condensable organic (condensed organics $+\mathrm{C}_{4+}$ in gas) of $26 \mathrm{wt} . \%$ dry as free (daf) [2].

Dayton et al.[6-8] also investigated catalytic hydropyrolysis of wood in a fluid bed reactor. Using a reduced NiMo hydrotreating catalyst they investigated the effect of the pressure by varying the total pressure between 10.3 and 20.7 bar and varying the hydrogen concentration between 20 and $60 \%$ [8]. They found that the char yield increased at low hydrogen partial pressure and that higher partial pressure of hydrogen decreased the oxygen content and increased the carbon content in the organic phase favoring the formation of hydrocarbons [8]. Furthermore, conducting catalytic hydropyrolysis at $450^{\circ} \mathrm{C}$ and using hydrogen at atmospheric pressure with a molybdenum based reduced metal oxide catalyst resulted in a carbon recovery in the organic phases and $\mathrm{C}_{4+}$ of $43 \%$ and an oxygen content of $6.2 \mathrm{wt} . \%$ [7]. The results show that catalytic hydropyrolysis can be conducted at low pressure with a high yield and reasonable degree of deoxygenation. 
Several groups have investigated catalytic hydropyrolysis using Pyroprobe reactors and H-ZSM-5, often impregnated with $\mathrm{Ni}$ [9-15]. Melligan et al.[15] investigated the effect of hydrogen pressure at $600{ }^{\circ} \mathrm{C}$ using a $\mathrm{Ni} / \mathrm{H}-\mathrm{ZSM}-5$ catalyst and found that increasing the hydrogen pressure increased the higher heating value (HHV) of the products, due to an increased degree of deoxygenation. Other groups have investigated hydropyrolysis either using a cyclone reactor or fluid bed reactor followed by a fixed bed catalytic HDO reactor [16-19].

In our previous study [20] we investigated the effect of pressure and temperature on catalytic hydropyrolysis of beech wood using a two-reactor system, where the catalytic hydropyrolysis took place in a fluid bed reactor with a sulfided $\mathrm{CoMo} / \mathrm{MgAl}_{2} \mathrm{O}_{4}$ catalyst followed by a fixed bed reactor with a sulfided $\mathrm{NiMo} / \mathrm{Al}_{2} \mathrm{O}_{3}$ catalyst. Operating the fluid bed reactor at $450{ }^{\circ} \mathrm{C}$ and varying the total pressure between 16 and 36 bar did not have an impact on the condensed organics and $\mathrm{C}_{4+}$ gas yield [20]. The spent catalysts were not investigated. In this study we have conducted a more thorough investigation of the effect of the total pressure and the hydrogen partial pressure. The total pressure has been varied between 5.0 and 36 bar and the hydrogen partial pressure has been varied between 3.0 and 35.8 bar. The liquid products have been extensively characterized and the carbon content on the spent catalysts from both the HDO reactor and fluid bed reactor has been measured to indicate catalyst deactivation by coking.

\section{Material and methods}

\subsection{Biomass feedstock}

Bark free beech wood was used as biomass feedstock and was supplied by Dansk Træmel (Product number: 10000251250390). The moisture and ash contents were $6.72 \mathrm{wt.} \%$ (dried at $105^{\circ} \mathrm{C}$ ) and $0.59 \mathrm{wt} . \%$ on dry basis (db), respectively. The particle sizes were between 200-700 $\mu \mathrm{m}$. The beech wood was analyzed by Celignis Analytical (analysis P10) and consisted of 24 wt.\% db lignin, 40 wt.\% db cellulose, 18 wt.\% db hemicellulose, $3 \mathrm{wt} . \% \mathrm{db}$ other polysaccharides, $3 \mathrm{wt} . \% \mathrm{db}$ extractives and $12 \mathrm{wt} . \% \mathrm{db}$ unknown. A detailed elemental composition of the biomass, including the ash composition, can be found elsewhere [20]. 


\subsection{Catalysts}

A CoMo/ $\mathrm{MgAl}_{2} \mathrm{O}_{4}$ catalyst was used in the fluid bed reactor. The catalyst was received as extrudates and was crushed and sieved to a particle size between 180 and $355 \mu \mathrm{m}$. An extruded $\mathrm{NiMo} / \mathrm{Al}_{2} \mathrm{O}_{3}$ catalyst was used in the HDO reactor, and was used as received. Both catalysts were supplied by Haldor Topsøe A/S and were also used in our previous work [20]. These two catalysts were chosen due to their well-known activity in HDO reactions [21-30], where the NiMo catalyst mainly promotes the removal of oxygen from phenols after it has saturated the aromatics (HDO pathway), while the CoMo to a larger extent promotes the direct removal of oxygen from phenol (DDO pathway) [27,31-34]. At the applied temperatures in the fluid bed reactor the hydrogenation/deoxygenation of phenols are controlled by the thermodynamic equilibrium [20], thus it has been shown that the CoMo catalyst is the best choice for the fluid bed reactor [35]. In addition a catalyst with $\mathrm{MgAl}_{2} \mathrm{O}_{4}$ as support material was chosen for the fluid bed reactor because of its relatively high mechanical strength, which decreases the catalyst loss due to attrition.

\subsection{Experimental setup}

The catalytic hydropyrolysis experiments were conducted in a bench scale setup shown in Figure 1 . The setup is described in detail elsewhere [20]. The setup consisted of a feeding system, which included a gas mixing system and a screw feeder for biomass feeding, a fluid bed hydropyrolysis reactor, a filter for char removal, a fixed bed hydrotreating reactor, which can be bypassed, and a three stage condensation system $\left(20^{\circ} \mathrm{C}, 2^{\circ} \mathrm{C}\right.$, and $\left.-40^{\circ} \mathrm{C}\right)$. The temperature in the last step in the condensation system was in some experiments increased to $-20^{\circ} \mathrm{C}$, to avoid plugging of the heat exchanger due to formation of wax. The uncondensed gases were sent to a flare. A small fraction of the gas was sent to an online gas chromatograph (GC), which measured the gas composition $\left(\mathrm{H}_{2}, \mathrm{~N}_{2}, \mathrm{H}_{2} \mathrm{~S}, \mathrm{CO}, \mathrm{CO}_{2}, \mathrm{C}_{1}\right.$ to $\mathrm{C}_{5}$ and $\mathrm{C}_{6+}$ hydrocarbons) every $10 \mathrm{~min}$. The tubes between the fluid bed, filter and condensation section were heated to $350^{\circ} \mathrm{C}$ in order to avoid condensation. The biomass feeding tube was preheated to approximately $200^{\circ} \mathrm{C}$ to preheat the biomass and carrier gas while avoiding premature pyrolysis. 
The total mass of the condensed liquid was determined by weighing and the organic phase and the aqueous phase were separated with a separation funnel. In experiment 1-4 the mass of the condensed organics and aqueous were determined as described in ref. [20], while in experiment 5-8 the mass of the aqueous phase was measured and the mass of the organic phase was determined by subtracting the mass of the aqueous phase from the total mass of condensed liquid. The differences between these two methods are below the experimental uncertainty. The $\mathrm{H}_{2} \mathrm{~S}$ dissolved in the liquid phases was for safety reasons removed by bubbling with $\mathrm{N}_{2}$ until hydrogen sulfide test strips (Sigma Aldrich) showed no sign of $\mathrm{H}_{2} \mathrm{~S}$. This lead to a mass loss between 1.2 and $7.9 \mathrm{wt} . \%$ for the organic phase and between 0.43 and 5.1 wt.\% of the aqueous phase. The mass loss in the organic phase was mainly due to vaporization of light hydrocarbons while the mass loss in the aqueous phase was mainly due to vaporization of water.

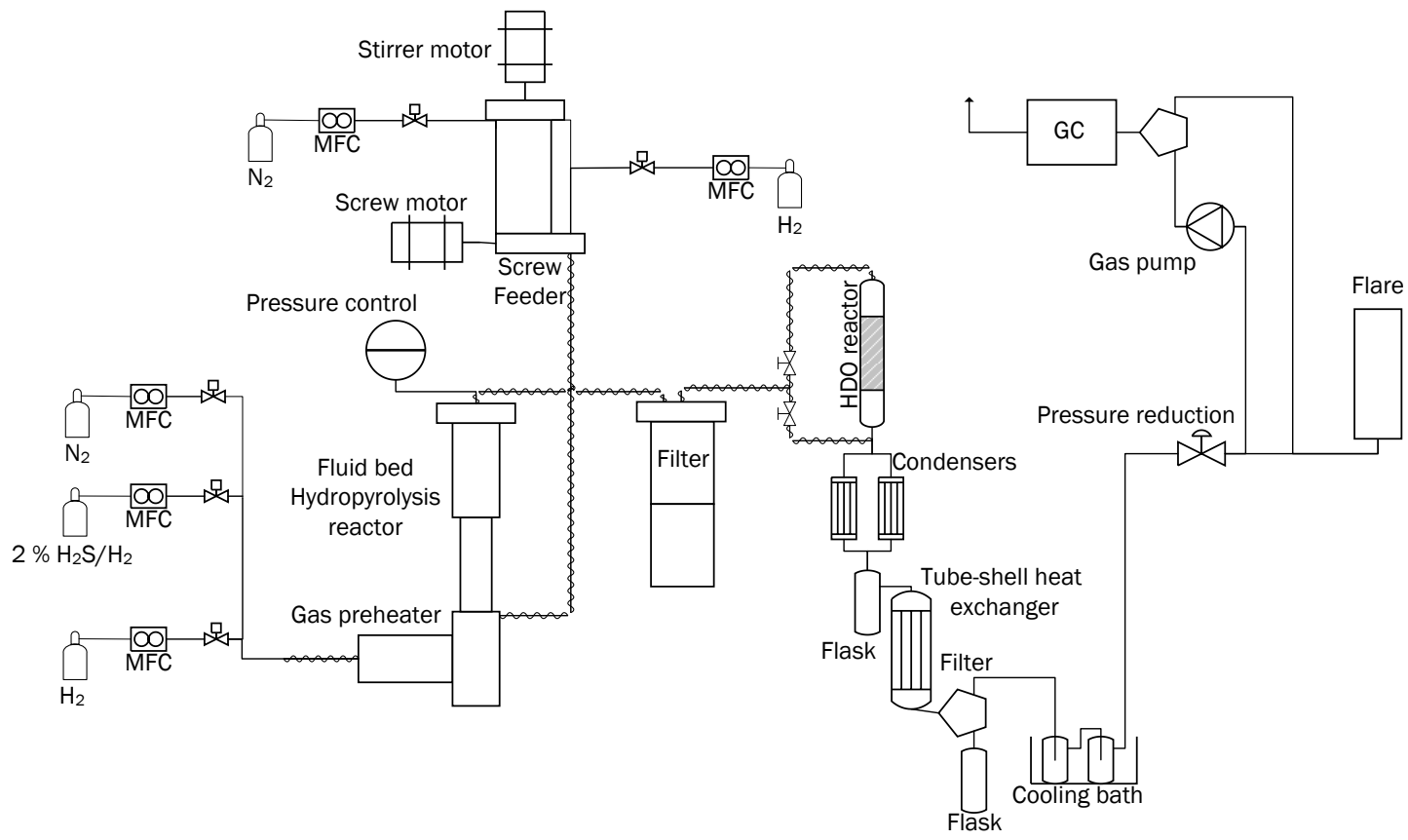

Figure 1. Simplified piping and instrumentation diagram of the catalytic hydropyrolysis setup

After each experiment the catalyst and the remaining char was removed from the fluid bed, and replaced with fresh catalyst for the subsequent experiment. The same catalyst was used in the HDO reactor in experiments 1 to 4 , but the catalyst in the HDO reactor was replaced before experiments 5, 6, and 7 . The 
solid yield was defined as the sum of the char (un-vaporized biomass particles) and coke (carbon on the catalyst) yield, and was calculated by subtracting the mass of loaded catalyst from the total mass of solids collected from the filter and fluid bed.

In experiments 1 to 4 a liquid feeding system consisting of a pump and evaporator was used to supply the setup with dimethyl disulfide (DMDS) during the sulfidation of the catalysts, more information can be found in ref. [20]. However, DMDS lead to coking of the gas preheater and bottled $\mathrm{H}_{2} \mathrm{~S}$ was therefore used in experiments 5 to 8 . The catalysts were sulfided at 26 bar by heating the reactors from 180 to $350{ }^{\circ} \mathrm{C}$ with $1.8 \mathrm{~mol} \mathrm{\%} \mathrm{H}_{2} \mathrm{~S}, 11 \mathrm{~mol}^{\%} \mathrm{~N}_{2}$ in $87 \% \mathrm{H}_{2}$ by feeding $2 \% \mathrm{H}_{2} \mathrm{~S}$ in $\mathrm{H}_{2}$ (flow: $4 \mathrm{NL} / \mathrm{min}$ ) and $\mathrm{N}_{2}$ (flow: $0.5 \mathrm{NL} / \mathrm{min}$ ). The temperature ramp was $10{ }^{\circ} \mathrm{C} / \mathrm{min}$ and the holding time was 3 hours, when both reactors were used and 2 hours when only the fluid bed reactor was used.

The experimental error is less than $0.2 \mathrm{wt} . \%$ daf for the $\mathrm{C}_{1}-\mathrm{C}_{3}$ yield, $0.5 \mathrm{wt} . \%$ daf for the total $\mathrm{CO}$ and $\mathrm{CO}_{2}$ yield, $0.5 \mathrm{wt} . \%$ daf for the char and coke yield, $0.5 \mathrm{wt} . \%$ daf for the condensable organic yield (condensed organics and $\mathrm{C}_{4+}$ in the gas), and $1.5 \mathrm{wt} . \%$ daf for the aqueous phase yield, when the mass balance closes within 99 wt.\% daf [36]. However, it should be noted that the experimental uncertainty increases with decreasing mass balance closure.

\subsection{Analysis methods}

\subsubsection{Organic phase}

The produced organic phases were analyzed with several different methods and a detailed description of the methods can be found elsewhere[20]. The hydrogen and sulfur content was measured with ASTM method D7171 and ASTM method D4294, respectively. The viscosity at $40{ }^{\circ} \mathrm{C}$ was measured with ASTM method D7042, the density at $40{ }^{\circ} \mathrm{C}$ was measured with ASTM method D4052. The water content was measured with Karl Fisher titration. The total acid number (TAN) was measured at DB lab by titration with $\mathrm{KOH}$. 
141 For the organic phases with less than 2 wt.\% oxygen, the oxygen content was measured using a GC with an atomic emission detector (AED). The GC was an Agilent 7890 coupled to a JAS 2370 AED in oxygen selective mode. The total amount of oxygen in the samples was quantified by adding a known amount of 4fluorophenol to the sample. For organic phases with more than 2 wt.\% oxygen, the oxygen content was analyzed at DB Lab A/S using a Flash 2000 elemental analyzer (Thermo Scientific). The uncertainty of this measurement was $3.0 \%$, defined as two standard deviations for the measurement uncertainty, corresponding to a confidence interval of $95 \%$.

Selective analysis of the sulfur containing compounds in the condensed oil was conducted using the above described GC with the AED detector in sulfur specific mode. Quantification was done by adding known amounts of benzothiophene, dibenzothiophene and 4-methyl-dibenzothiophene to the sample.

151 The condensed organic liquid samples were characterized by GCXGC-time of flight (ToF)/ mass 152 spectrometry (MS) or -flame ionization detector (FID) using a LECO $^{\circledR}$ Pegasus $4 \mathrm{D}^{\mathrm{TM}}$ instrument. The 153 instrument included an Agilent 7890A GC equipped with a Gerstel ${ }^{\circledR}$ CIS 4 PTV inlet, a secondary oven, a 154 quad-jet, dual-stage cryogenic (liquid $\mathrm{N}_{2}$ ) modulator, a Tof/MS, and a FID detector. The primary (1D) and secondary (2D) columns were Restek ${ }^{\circledR}$ Rxi-5Sil MS and Restek ${ }^{\circledR}$ Rxi-17Sil MS, respectively. Based on the GCXGC-ToF/MS analysis the compounds were classified into eleven classes: naphthenes, monoaromatics, 157 diaromatics, triaromatics, larger aromatics, phenols, dihydroxybenzenes, larger oxygenated aromatics, oxygenated aliphatics, paraffins, and sterols. Based on the paraffins retention time on the 1D column the component classes where divided into subgroups on the basis on the number of carbon atoms in the molecules : - $\mathrm{C} 10, \mathrm{C} 11-\mathrm{C} 15, \mathrm{C} 16-\mathrm{C} 20$, and $\mathrm{C} 20+$. However, it should be noted that other component classes do not necessarily have the same carbon number distribution as the paraffins, thus caution is needed when 162 correlating the relative amount of each subgroup with its carbon number distribution. The relative amount 163 (FID area-\%) of each compound class was estimated as the sum of areas of all detected peaks in that class 
divided by the total peak area of all compound classes. All data was processed using the ChromaTof ${ }^{\circledast} 4.50$ software.

\subsubsection{Aqueous phase}

The carbon content in the aqueous phase was determined with GC-AED. The quantification was done by external standards using benzyl alcohol dissolved in water. Calibration concentrations ranged from $10 \mathrm{ppm}$ to $1100 \mathrm{ppm}$ carbon. No identification of individual compounds was done and the total detected carbon was taken as a figure of the total carbon content in the aqueous sample. No sample pretreatment was done prior to analysis. A more thorough description of the method can be found elsewhere[36].

The aqueous phase was also analyzed on a Shimadzu GC-MS/FID with a Supelco Equity-5 column. The compounds were identified on the MS and quantified using the parallel FID. Based on the GC-FID/MS analysis the components were classified into 8 groups: unidentified, ethers, ketones, alcohols, sugars, phenols, acids and furans. The relative amount (FID area-\%) of each component class was estimated as the sum of all the detected peaks in that class divided by the total peak area.

\subsubsection{Catalyst characterization}

The carbon content on the spent $\mathrm{NiMo} / \mathrm{Al}_{2} \mathrm{O}_{3}$ catalyst from the $\mathrm{HDO}$ reactor was measured with a LECO CS200. The sample was combusted in an $\mathrm{O}_{2}$ atmosphere and the formed $\mathrm{CO}_{2}$ was measured with IRabsorption.

The catalyst in the fluid bed reactor was during the experiment mixed with char particles, which makes it difficult to measure that carbon content on the spent catalyst from the fluid bed by combustion. The carbon content on the spent catalysts from the fluid bed reactor was therefore measured with scanning electron microscopy (SEM) combined with an energy-dispersive detector (EDS), and a detailed description of the method can be found elsewhere [36]. A FEI QUANTA600 scanning electron microscope with tungsten filament and equipped with a liquid nitrogen cooled EDAX EDS detector was used for these measurements. EDS element quantification was conducted at four different acceleration voltages: $3 \mathrm{kV}, 5 \mathrm{kV}, 10 \mathrm{kV}$, and 15 
$\mathrm{kV}$ to probe different interaction volumes between the incident electron beam and the sample. The maximum penetration depth for $\mathrm{MgAl}_{2} \mathrm{O}_{4}$ was estimated with CASINO Monte Carlo Software to be approximately $0.170 \mu \mathrm{m}$ for $3 \mathrm{kV}$ and $1.60 \mu \mathrm{m}$ for $15 \mathrm{kV}$ [36], thus mainly probing the composition close to the catalyst surface. The standard deviation for the measurement was $1.5 \mathrm{wt} . \%$ at $3 \mathrm{kV}, 0.8 \mathrm{wt} . \%$ at $5 \mathrm{kV}$,

\section{Results and Discussion}

194 The tested process conditions and their effect on the product distribution are shown in Table 1. It should be 195 noted that experiment 1-4 has previously been published [20]. However, in this work the produced liquid phases and the spent catalysts have been more extensively characterized and combining the previous obtained results with the new results gives a more in-depth understanding of the effect of pressure. The feed time varied between 1.4 and 4.0 hours and the mass balance closed between 99.5 and 92.1 wt.\% daf. The reason for the short feeding time of 1.4 hours in experiment 6 is that the tube between fluid bed reactor and filter plugged. This was probably due to condensation and polymerization of heavy oxygenates in the tube. The mass balance in experiment 8 only closed with $92.1 \mathrm{wt} . \%$ daf. In this experiment the HDO reactor was bypassed, the total pressure was 10 bar and the hydrogen partial pressure only 3.0 bar. The produced organic phase was thus heavier than the aqueous phase and part of the reason for the poor mass balance in experiment 8 , is therefore most likely due to accumulation of organics in the setup. The biomass on the results [20]. 
Table 1 Summary of the reactions conditions and mass balances for catalytic hydropyrolysis of beech wood at different total and hydrogen partial pressures.

\begin{tabular}{|c|c|c|c|c|c|c|c|c|}
\hline Test & 1 & 2 & 3 & 4 & 5 & 6 & 7 & 8 \\
\hline \multicolumn{9}{|l|}{ Test conditions } \\
\hline & With & Without & With & With & With & With & With & Without \\
\hline & HDO & HDO & HDO & HDO & HDO & HDO & HDO & HDO \\
\hline FB temperature $\left({ }^{\circ} \mathrm{C}\right)$ & 451 & 450 & 447 & 449 & 452 & 450 & 450 & 454 \\
\hline $\begin{array}{l}\text { FB catalyst amount } \\
\text { (g) }\end{array}$ & 50.1 & 49.6 & 49.7 & 50.2 & 50.0 & 50.0 & 50.1 & 50.0 \\
\hline $\begin{array}{l}\text { HDO temperature } \\
\left({ }^{\circ} \mathrm{C}\right)\end{array}$ & 371 & - & 370 & 364 & 386 & 383 & 376 & - \\
\hline HDO catalyst mass (g) & 173 & - & 173 & 173 & 175 & 175 & 171 & - \\
\hline Total pressure (bar) & 26 & 26 & 16 & 36 & 10 & 5 & 10 & 10 \\
\hline $\mathrm{H}_{2}$ pressure (bar) & 24.5 & 25.8 & 15.9 & 35.8 & 8.2 & 3.0 & 3.0 & 3.0 \\
\hline Feed time $(\mathrm{h})$ & 4.0 & 3.9 & 4.0 & 4.0 & 2.6 & 1.4 & 2.8 & 2.8 \\
\hline Feeding rate $(\mathrm{g} / \mathrm{h})$ & 250 & 174 & 161 & 159 & 354 & 389 & 350 & 350 \\
\hline $\mathrm{H}_{2} \mathrm{~S}$ conc. $(p p m)$ & 460 & 48 & 47 & 50 & 475 & 460 & 464 & 464 \\
\hline $\mathrm{H}_{2}$ flow $(\mathrm{NL} / \mathrm{min})$ & 82 & 87 & 52.4 & 124.2 & 30.9 & 10.4 & 11.4 & 11.4 \\
\hline $\mathrm{N}_{2}$ flow $(\mathrm{NL} / \mathrm{min})$ & 5.0 & 0.62 & 0.37 & 0.62 & 7.0 & 7.0 & 26.5 & 26.5 \\
\hline \multicolumn{8}{|l|}{$\overline{\text { Biomass used }(\mathrm{kg})}$} & 9.4 \\
\hline \multicolumn{9}{|l|}{ Yields (wt. daf \%) } \\
\hline Gas & 31.5 & 27.4 & 30.3 & 26.3 & 32.1 & 33.2 & 33.5 & 24.0 \\
\hline Solid & 11.4 & 12.3 & 11.0 & 12.7 & 13.2 & 13.6 & 15.7 & 15.3 \\
\hline Aqueous phase & 35.2 & 37.0 & 33.2 & 37.7 & 32.3 & 29.0 & 28.8 & 27.5 \\
\hline Organic phase & 12.3 & 12.0 & 11.0 & 10.6 & 13.0 & 10.1 & 12.6 & 23.0 \\
\hline $\mathrm{C}_{4+}$ in the gas & 9.1 & 8.3 & 8.7 & 10.3 & 7.9 & 8.5 & 7.6 & 2.3 \\
\hline Organics $+\mathrm{C}_{4+}$ & 21.5 & 20.3 & 19.7 & 20.9 & 20.9 & 18.7 & 20.2 & 25.3 \\
\hline Mass balance & 99.5 & 96.9 & 94.2 & 97.6 & 97.5 & 94.5 & 98.2 & 92.1 \\
\hline \multicolumn{9}{|l|}{ Carbon recovery (\%) } \\
\hline $\mathrm{C}_{1}-\mathrm{C}_{3}$ & 23 & 19 & 19 & 21 & 22 & 21 & 21 & 8 \\
\hline $\mathrm{C}_{4+}$ & 15 & 14 & 14 & 17 & 13 & 15 & 13 & 4 \\
\hline $\mathrm{CO}+\mathrm{CO}_{2}$ & 12 & 13 & 13 & 10 & 13 & 15 & 16 & 13 \\
\hline Organic phase & 21 & 21 & 19 & 19 & 23 & 16 & 19 & 30 \\
\hline Aqueous phase & 0.014 & 1.1 & $<0.008$ & $<0.009$ & 0.51 & 0.59 & 0.47 & 8.5 \\
\hline Organic phase $+\mathrm{C}_{4+}$ & 37 & 35 & 34 & 36 & 36 & 31 & 32 & 34 \\
\hline \multicolumn{9}{|c|}{ Organic phase composition } \\
\hline Water (wt.\%) & ND & 0.35 & ND & ND & 0.36 & 3.32 & 1.6 & 11.3 \\
\hline$C^{*}(w t . \% d b)$ & 88 & 88 & 88 & 88 & 87 & 84 & 83 & 74 \\
\hline $\mathrm{H}(w t . \% \mathrm{db})$ & 11.9 & 10.2 & 11.2 & 11.6 & 9.58 & 9.55 & 9.56 & 7.60 \\
\hline$O(w t . \% d b)$ & 0.003 & 1.8 & 0.0009 & 0.0001 & 3.3 & 6.0 & 7.8 & 18.3 \\
\hline $\mathrm{S}(\mathrm{wt} . \% \mathrm{db})$ & 0.117 & 0.303 & 0.417 & 0.246 & 0.036 & 0.045 & 0.033 & 0.093 \\
\hline \multicolumn{9}{|c|}{ Organic phase physical properties } \\
\hline $\begin{array}{l}\text { Density at } 40^{\circ} \mathrm{C} \\
(\mathrm{g} / \mathrm{ml})\end{array}$ & 0.827 & 0.889 & 0.852 & 0.843 & 0.863 & .0936 & 0.944 & 1.06 \\
\hline Viscosity (Pa s) & $8.70 \times 10^{-4}$ & $1.43 \times 10^{-3}$ & $1.04 \times 10^{-3}$ & $1.01 \times 10^{-3}$ & $9.81 \times 10^{-4}$ & $2.69 \times 10^{-3}$ & $3.39 \times 10^{-3}$ & $9.29 \times 10^{-3}$ \\
\hline TAN (mgкон/g) & - & - & - & - & - & - & 0.25 & 88.60 \\
\hline \multicolumn{9}{|c|}{ Aqueous phase composition (wt.\%) } \\
\hline $\mathrm{C}$ & 0.017 & 1.3 & $<0.01$ & $<0.01$ & 0.66 & 0.81 & 0.7 & 12.3 \\
\hline \multicolumn{9}{|c|}{ Gas composition (wt.\% daf) } \\
\hline $\mathrm{CO}$ & 9.0 & 11.1 & 10.8 & 9.9 & 8.8 & 10.0 & 10.0 & 8.7 \\
\hline $\mathrm{CO}_{2}$ & 8.1 & 5.7 & 7.6 & 3.3 & 10.3 & 12.4 & 12.9 & 10.8 \\
\hline $\mathrm{C}_{1}-\mathrm{C}_{3}$ & 14.3 & 12.1 & 12.0 & 13.2 & 13.0 & 10.9 & 10.6 & 4.5 \\
\hline $\mathrm{C}_{4+}$ & 9.1 & 8.3 & 8.7 & 10.3 & 7.9 & 8.5 & 7.6 & 2.3 \\
\hline
\end{tabular}

*By difference 


\subsection{Product distribution}

The main effect on the product distribution by increasing the hydrogen partial pressure was that it increased the aqueous phase yield and decreased the $\mathrm{CO}$ and $\mathrm{CO}_{2}$ yield. This shows that when the hydrogen pressure is increased the hydrodeoxygenation activity increases while the carboxylation/carbonylation decreases. In addition, decreasing the hydrogen partial pressure to below 15.9 bar hydrogen (experiment 58) lead to an increase in the char and coke yield, which indicates that at low hydrogen pressure the catalyst is not active enough to suppress polymerization reactions. Varying the total pressure at constant hydrogen partial pressure (experiment 6 and 7) did not have a significant impact on the product distribution, thus the observed effects are due to the variations in hydrogen pressure.

In the experiments where both reactors were used the condensable organic yield (condensed organics $+\mathrm{C}_{4+}$ in the gas) varied between 18.7 and 21.5 wt.\% daf, as shown in Figure 2(A), with no apparent correlation between the hydrogen pressure and condensable organic yield. However, when the HDO reactor was bypassed the condensable organic yield was $20.3 \mathrm{wt} . \%$ daf at 25.8 bar hydrogen and increased to $25.3 \mathrm{wt} . \%$ daf at 3.0 bar hydrogen. The reason for the increased condensable organic yield is due to increased oxygen content in the organic phase. Using the HDO reactor, the total gas yield (Figure 2(B)) decreased from 33.5 to 26.3 wt.\% daf when partial pressure of hydrogen was increased from 3.0 to 35.8 bar. This was due to a decrease in the $\mathrm{CO}$ and $\mathrm{CO}_{2}$ yield, which decreased from 22.9 wt.\% daf at 3.0 bar to 13.2 wt.\% daf at 35.8 bar, while the $\mathrm{C}_{1}-\mathrm{C}_{3}$ yield varied between 10.6 and 14.3 wt.\% daf. The $\mathrm{CO}$ and $\mathrm{CO}_{2}$ yield most likely decreased due to a higher hydrodeoxygenation activity at higher hydrogen partial pressure, which is a competing reaction with decarbonylation and decarboxylation. The lower $C_{1}-C_{3}$ yield when the HDO reactor is bypassed, 4.5 wt.\% daf at 3.0 bar hydrogen and 10.6 wt.\% at 25.8 bar hydrogen, could be due to cracking of the vapors in the HDO reactor, but it is probably also due to deoxygenation of $C_{1}-C_{3}$ oxygenates, which are recovered in the aqueous and organic phases when the HDO reactor is bypassed. Interestingly, the CO and $\mathrm{CO}_{2}$ yield is unchanged when the HDO reactor is bypassed at 25.8 bar hydrogen, but decreased from 22.9 to 19.6 wt.\% daf at 3.0 bar hydrogen. 
As shown in Figure 2(C) the solid yield decreased from $15.7 \mathrm{wt} . \%$ daf at 3.0 bar hydrogen to $11 \mathrm{wt} \%$ at 15.9 bar hydrogen. Furthermore, at 3.0 bar hydrogen it was observed that coke builds up on the filter and the filter cake was approximately $0.5 \mathrm{~cm}$ thick (see supplementary material Figure S.1). Similarly Dayton et al. [8] observed that decreasing the hydrogen concentration from 40 to $20 \%$ (at 20.7 bar total pressure and $425{ }^{\circ} \mathrm{C}$ ) increased the solid yield from 8.9 to $14.1 \mathrm{wt} . \%$. This indicates that the catalyst in the fluid bed reactor is not able to sufficiently fast remove the reactive oxygenates, leading to increased polymerization reactions. Furthermore, the solid yield increased to $12.7 \mathrm{wt} . \%$ daf when the hydrogen pressure was increased to 35.8 bar, which could indicate that too high pressure also increases the solid yield. However, the increase is close to the experimental uncertainty. The aqueous phase yield increased with increasing hydrogen pressure from 28.8 wt.\% daf at 3.0 bar hydrogen to $37.7 \mathrm{wt} . \%$ daf at 35.8 bar hydrogen, see Figure 2(D). This increase is both due to an increased degree of hydrogenation and hydrodeoxygenaton of the organics, and decreased carboxylation/carbonylation reactions. The change in aqueous phase yield, when the HDO reactor is bypassed is within the experimental uncertainty, however, bypassing the HDO reactor increased the carbon content in the aqueous phase, which is discussed in section 3.2.

In both experiments 6 and 7 the hydrogen partial pressure was 3.0 bar, but in experiment 6 the total pressure was 5 bar, while it was 10 bar in experiment 7. The difference in the condensable organic, $\mathrm{CO}+\mathrm{CO}_{2}, \mathrm{C}_{1}-\mathrm{C}_{3}$, and aqueous phase yields in these two experiments where $0.6 \mathrm{wt} . \%$ daf or lower. The largest difference was in the solid yield, which was $13.6 \mathrm{wt} . \%$ daf in experiment 6 (5 bar) and $15.7 \mathrm{wt} . \%$ daf the tube, which was therefore not accounted for in the mass balance. Therefore, considering the relatively large difference in the product distribution (>2 wt.\% for $\mathrm{CO}+\mathrm{CO}_{2}, \mathrm{C}_{1}-\mathrm{C}_{3}$, solid and aqueous phase yield) between experiment 5 (10 bar pressure, 8.2 bar hydrogen) and 7 (10 bar pressure, 3 bar hydrogen), the not on the total pressure. 

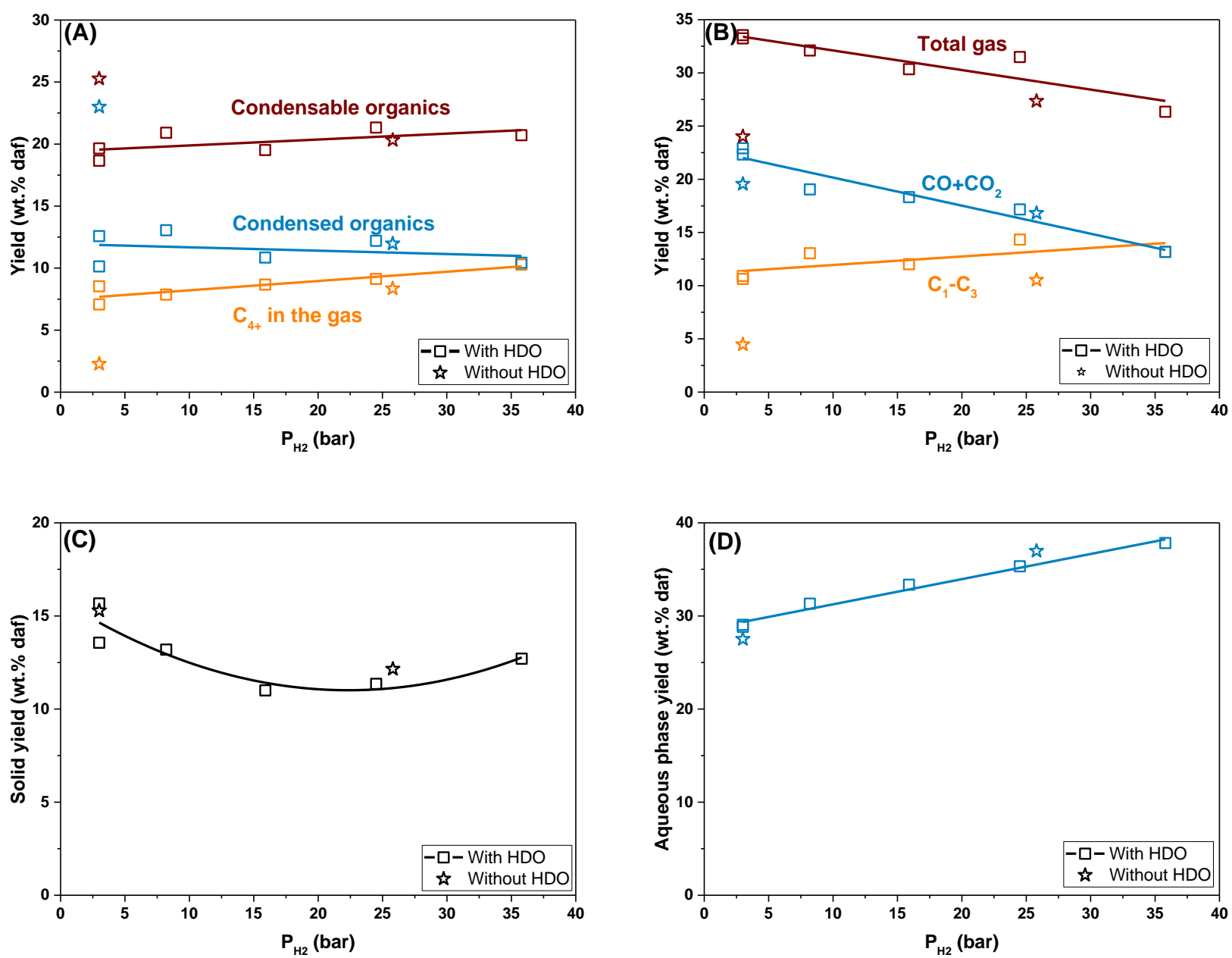

Figure 2 Effect of hydrogen partial pressure on the condensable organic yield (A), gas yield (B), char yield (C), and aqueous phase yield (D). The lines provided are trend lines. Conditions: fluid bed temperature $447-454{ }^{\circ} \mathrm{C}$, $\mathrm{HDO}$ temperature: $364-386{ }^{\circ} \mathrm{C}$, biomass feeding rate: $159-389 \mathrm{~g} / \mathrm{min}, \mathrm{H}_{2} \mathrm{~S}$ concentration: 47-475 ppm, $\mathrm{H}_{2}$ flow: 11.4-124.4 NL/min, $\mathrm{N}_{2}$ flow: 0.37-26.5 NL/min.

The $\mathrm{CO}$ and $\mathrm{CO}_{2}$ yield is shown in Figure 3(A). The $\mathrm{CO}$ yield varied between 8.8 and $11.1 \mathrm{wt} . \%$ daf, and no correlation between the $\mathrm{CO}$ yield and the hydrogen pressure was observed. While the $\mathrm{CO}_{2}$ yield decreased from 12.9 wt.\% daf at 3.0 bar hydrogen to $3.3 \mathrm{wt.} \%$ daf at 35.8 bar hydrogen. The reason for the decreasing $\mathrm{CO}_{2}$ yield might be that when the hydrogen pressure is increased, the $\mathrm{CO}_{2}$ is converted through the reverse water gas shift reaction (R.1).

$$
\mathrm{CO}_{2}+\mathrm{H}_{2} \rightleftharpoons \mathrm{CO}+\mathrm{H}_{2} \mathrm{O}
$$

The $C_{2}-C_{3}$ paraffin and olefin yields in Figure $3(B)$ show that when the HDO is used at hydrogen pressures between 15.9 and 35.8 bar all the olefins were converted into paraffins. However, at lower hydrogen pressures the olefin conversion decreased, thus at 8.2 bar hydrogen the $C_{2}-C_{3}$ olefin yield was 0.8 wt.\% daf 
and at 3.0 bar hydrogen the olefin yield was 3.1-3.3 wt.\% daf. Bypassing the HDO reactor increased the olefin yield to 1.5 wt.\% at 25.8 bar hydrogen, which shows that the olefins are removed in the HDO reactor at this pressure. However, bypassing the HDO reactor at 3.0 bar hydrogen decreased the olefin yield to 1.7 wt.\% daf, which is probably due to a higher yield of light oxygenates, which are not deoxygenated.
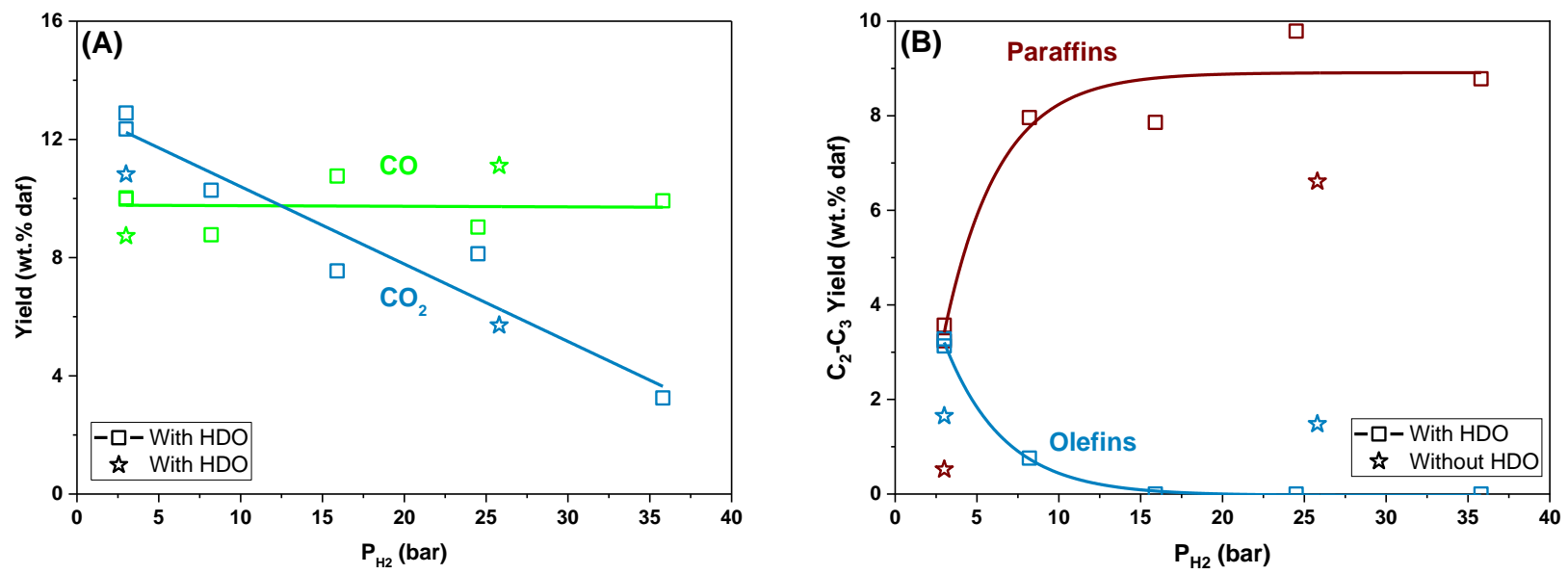

Figure 3 Effect of hydrogen partial pressure on the $\mathrm{CO}$ and $\mathrm{CO}_{2}$ yield $(A)$ and the $\mathrm{C}_{2}-\mathrm{C}_{3}$ paraffin and olefin yield (B). The lines provided are trend lines. Conditions: fluid bed temperature $447-454^{\circ} \mathrm{C}$, $\mathrm{HDO}$ temperature: $364-386^{\circ} \mathrm{C}$, biomass feeding rate: 159-389 g/min, $\mathrm{H}_{2} \mathrm{~S}$ concentration: 47-475 ppm, $\mathrm{H}_{2}$ flow: 11.4-124.4 NL/min, $\mathrm{N}_{2}$ flow: 0.37-26.5 NL/min.

\subsection{Chemical composition of the condensed liquids}

\subsubsection{Oxygen and hydrogen content}

The oxygen and hydrogen content in the condensed organic phase are shown in Figure 4. When the HDO

reactor was used the oxygen content was close to $0 \mathrm{wt} . \%$ at hydrogen pressures between 15.9 and 25.8

bar; however, decreasing the hydrogen pressure to 8.2 increased the oxygen content to $3.3 \mathrm{wt} . \% \mathrm{db}$ and 
Using the HDO reactor and increasing the hydrogen pressure from 3.0 to 24.5 bar increased the hydrogen content in the organic phase from 9.55 to $11.9 \mathrm{wt} . \% \mathrm{db}$, while further increasing the hydrogen pressure to 35.8 bar decreased the hydrogen content to $11.6 \mathrm{wt} . \% \mathrm{db}$. However, this decrease is most likely due to the experimental uncertainty. Bypassing the HDO reactor also decreased the hydrogen content in the condensed organic phase to $10.2 \mathrm{wt} . \% \mathrm{db}$ at 25.8 bar hydrogen and $7.60 \mathrm{wt} . \% \mathrm{db}$ at 3.0 bar hydrogen. The lower hydrogenation activity could also be seen on the lower hydrogen consumption at low hydrogen pressures, thus the hydrogen consumption was between 19 and $20 \mathrm{~g} \mathrm{H}_{2} / \mathrm{kg}$ biomass at 3.0 bar hydrogen which increased to $34 \mathrm{~g} \mathrm{H}_{2} / \mathrm{kg}$ biomass at 15.9 bar hydrogen and further increased to $46 \mathrm{~g} \mathrm{H}_{2} / \mathrm{kg}$ biomass at 24.5 and 35.8 bar hydrogen. The hydrogen consumption also decreased with approximately $10 \mathrm{~g} \mathrm{H}_{2} / \mathrm{kg}$ biomass when the HDO reactor was bypassed at both 3.0 and 25.8 bar hydrogen, indicating that the hydrogen consumed in the HDO reactor is independent of the pressure in the tested range. Dayton et al. [8] observed that the hydrogen consumption was between 20 to $25 \mathrm{~g} \mathrm{H}_{2} / \mathrm{kg}$ biomass when operating at 4.1 bar hydrogen and between 35 to $38 \mathrm{~g} \mathrm{H}_{2} / \mathrm{kg}$ biomass when operating at 8.2 bar hydrogen. The reason for the higher hydrogen consumption in the work by Dayton et al. is most likely that they used a reduced NiMo catalyst, while sulfided catalysts are used in this study, and reduced $\mathrm{Ni}$ is known for its high hydrogenation activity.
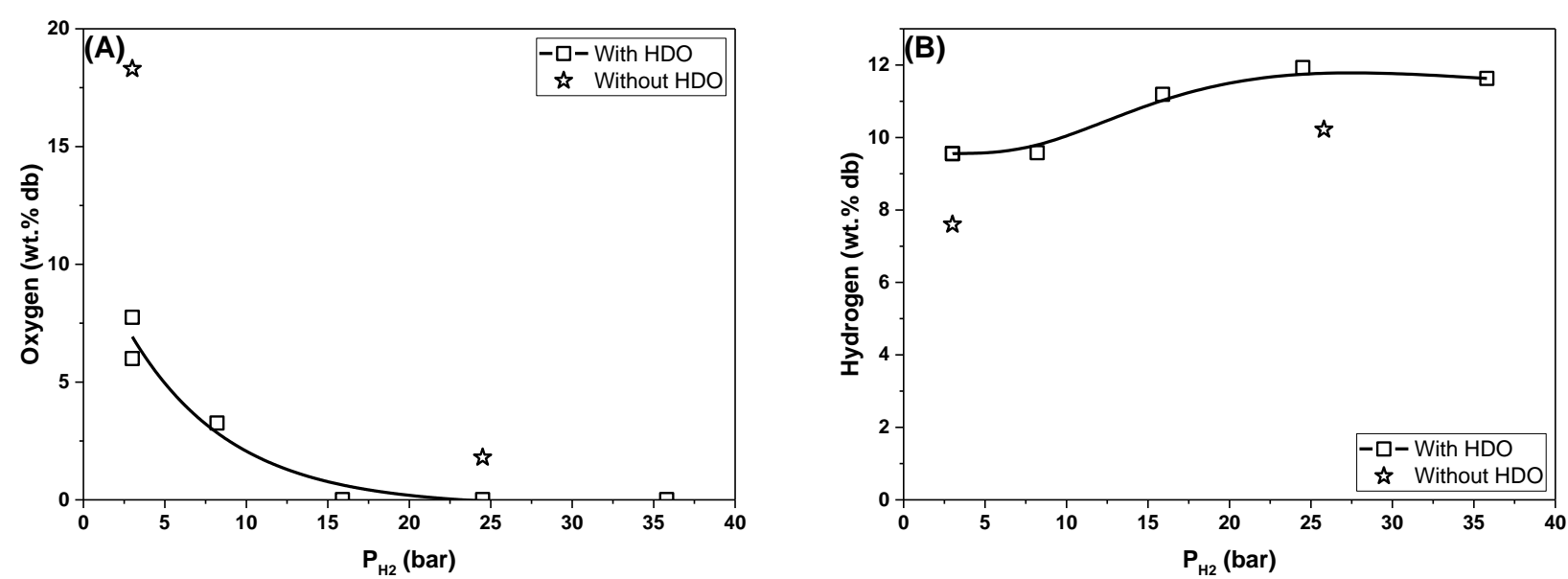

Figure 4 Effect of the hydrogen partial pressure on the oxygen (A) and hydrogen (B) content of the condensed organic phase. The lines provided are trend lines. Conditions: fluid bed temperature $447-454{ }^{\circ} \mathrm{C}$, HDO temperature: $364-386{ }^{\circ} \mathrm{C}$, biomass feeding rate: $159-389 \mathrm{~g} / \mathrm{min}, \mathrm{H}_{2} \mathrm{~S}$ concentration: $47-475 \mathrm{ppm}, \mathrm{H}_{2}$ flow: 11.4-124.4 NL/min, $\mathrm{N}_{2}$ flow: 0.37-26.5 NL/min. 


\subsubsection{Physical properties of the organic phase}

The density and the viscosity of the condensed organic phase were measured at $40{ }^{\circ} \mathrm{C}$ and are shown in Figure $5(\mathrm{~A})$ and $(\mathrm{B})$, respectively. Using the $\mathrm{HDO}$ reactor the density was between 0.936 and $0.944 \mathrm{~g} / \mathrm{ml}$ at 3.0 bar hydrogen, and increasing the hydrogen pressure to $24.5-35.8$ bar decreased the density to $0.827-$ $0.843 \mathrm{~g} / \mathrm{ml}$. Bypassing the HDO reactor increased the density to $1.0589 \mathrm{~g} / \mathrm{ml}$ at 3.0 bar hydrogen and 0.889 $\mathrm{g} / \mathrm{ml}$ at 25.8 bar hydrogen. The viscosity varied between $9.81 \times 10^{-4}$ and $1.01 \times 10^{-3} \mathrm{~Pa}$ s when the hydrogen pressure was between 8.2 and 35.8 bar and the HDO reactor was used. Decreasing the hydrogen pressure to 3.0 increased the viscosity to between $2.69 \times 10^{-3}$ and $3.39 \times 10^{-3} \mathrm{~Pa} \mathrm{~S}$, and bypassing the HDO reactor increased the viscosity to $1.43 \times 10^{-3} \mathrm{~Pa} \mathrm{~s}$ at 25.8 bar hydrogen and $9.29 \times 10^{-3} \mathrm{~Pa}$ s at 3.0 bar. The density of fast pyrolysis oil is typically between 1.1 and $1.3 \mathrm{~g} / \mathrm{ml}$ and the viscosity is between 0.014 and $0.13 \mathrm{~Pa}$ [ [5]. Therefore, and despite that both the density and viscosity increased significantly when the HDO reactor was bypassed at 3.0 bar they were still significantly lower than typical values for untreated fast pyrolysis oil. Furthermore, the density and viscosity of diesel is $0.82-0.85 \mathrm{~g} / \mathrm{ml}$ and $1.56-1.83 \times 10^{3} \mathrm{~Pa} \mathrm{~s}$, respectively [5]. This shows that the organic phases from the experiments with the HDO reactor were more similar to light gas oil than pyrolysis oil and due to the fairly low oxygen content in the organic phase it is most likely possible to co-feed into a refinery diesel hydrotreater.
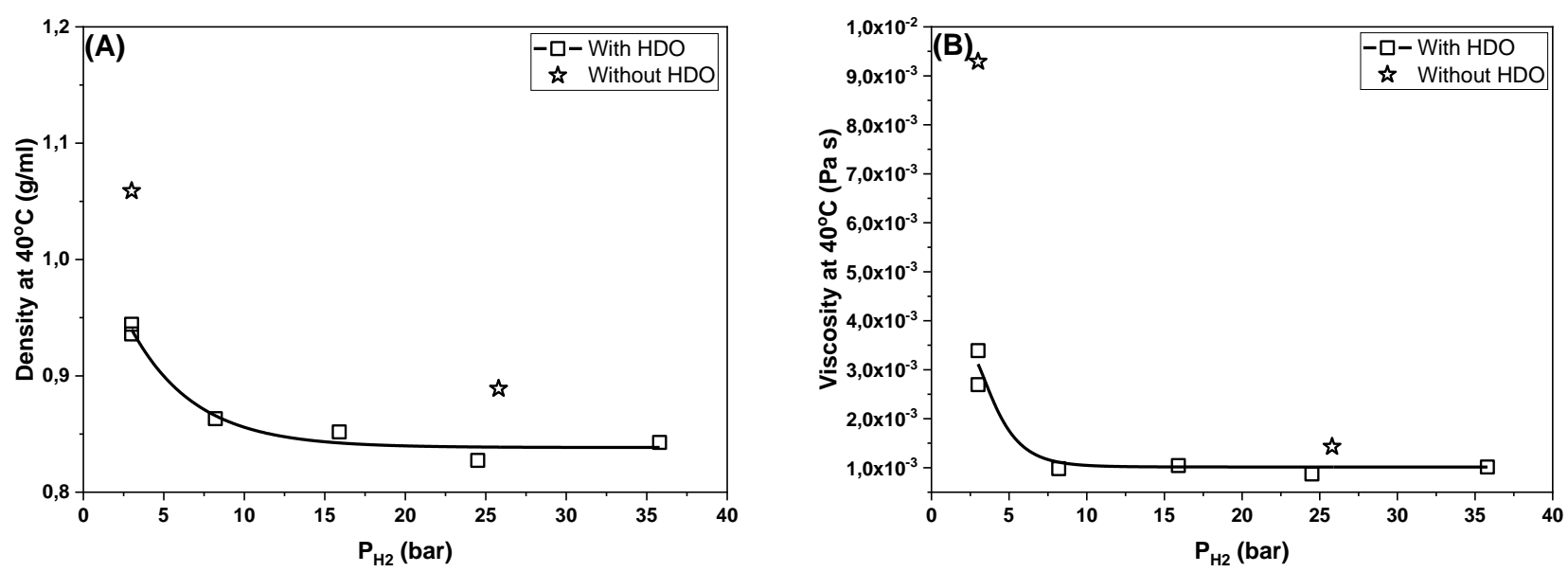

Figure 5 Effect of the hydrogen partial pressure on the density $(A)$ and viscosity $(B)$ of the condensed organic phase. The lines provided are trend lines. Conditions: fluid bed temperature $447-454{ }^{\circ} \mathrm{C}$, HDO temperature: $364-386{ }^{\circ} \mathrm{C}$, biomass feeding rate: $159-389 \mathrm{~g} / \mathrm{min}, \mathrm{H}_{2} \mathrm{~S}$ concentration: 47-475 ppm, $\mathrm{H}_{2}$ flow: 11.4-124.4 NL/min, $\mathrm{N}_{2}$ flow: 0.37-26.5 NL/min. 
The TAN number was also measured for the condensed organic phase from the experiments conducted at 3.0 bar hydrogen with (exp. 7) and without the HDO reactor (exp. 8). This showed that the TAN number for organic phase was $0.25 \mathrm{mg}_{\mathrm{\kappa oH}} / \mathrm{g}$ when the $\mathrm{HDO}$ reactor was used and $88.60 \mathrm{mg} \mathrm{\kappa oH} / \mathrm{g}$ when it was bypassed, indicating the HDO reactor is able to remove the acids, which are known for their ability to deactivate HDO catalysts by polymerization [37].

333

\subsubsection{GC $\times$ GC-MS/FID}

In order to gain a deeper insight into the condensed organic phases they were analyzed with GCxGCMS/FID and the detected components were divided into eleven groups naphthenes, monoaromatics, diaromatics, triaromatics, larger aromatics, phenols, dihydroxybenzenes, larger oxygenated aromatics, oxygenated aliphatics, paraffins, and sterols. The most important observation was that when the HDO reactor was used most of the oxygenates were phenols, showing that even at low hydrogen partial pressures the HDO reactor was able to remove the most reactive oxygenates (experiment 5-7). Bypassing the HDO reactor showed that the obtained bio-oil at 3 bar hydrogen (experiment 8) contained many reactive oxygenates and multifunctional phenols, thus likely making it more difficult to further upgrade in a refinery.

Using the HDO reactor the concentration of paraffins was between 1.2 and $4.6 \%$ area-FID, and the concentration of oxygenated aliphatics was between 1.5 and $2.6 \%$ area-FID when the hydrogen pressure was below 15.9 bar, but $0 \%$ area-FID at higher hydrogen pressures (see supplementary material Figure S.2). This indicates that even at low hydrogen pressures most of the reactive oxygenates are removed. The concentration of phenols and larger oxygenated aromatics are shown in Figure 6(A). The concentration of phenols was between 44 and $45 \%$ area-FID at 3.0 bar hydrogen, but decreased to $12 \%$ area-FID at 8.2 bar hydrogen and further increasing the hydrogen pressure lead to an almost complete removal of the phenols (non-detected). Similarly, the concentration of larger oxygenated aromatics decreased from between 4.5 and $5.4 \%$ area-FID at 3.0 bar hydrogen to $1.5 \%$ area-FID at 8.2 bar hydrogen; none were detected at higher hydrogen pressures. The concentration of naphthenes increased from $17 \%$ area-FID at 3.0 bar 
Interestingly, the concentration of monoaromatics increased from between 12 and $14 \%$ area-FID at 3.0 bar
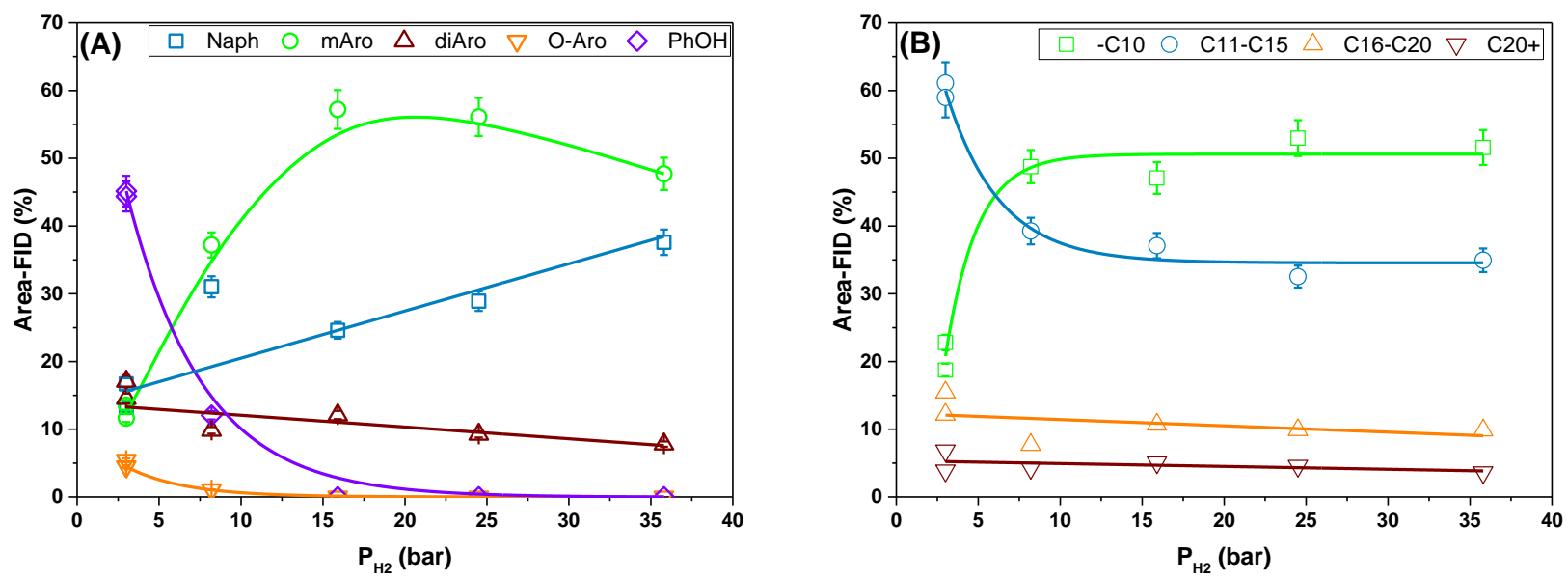

Figure 6 Effect of the hydrogen partial pressure on the concentration of naphthenes (Naph), monoaromatics (mAro), diaromatics (diAro), phenols (PhOH), and larger oxygenated aromatics (O-Aro) (A), and on the concentration of hydrocarbons with 10 or fewer carbon atoms (-C10), between 11 and 15 carbon atoms (C11-C15), between 16 and 20 carbon atoms (C16-C20), and more than 20 carbon atoms (C2O+) (B). The lines provided are trend lines. Conditions: fluid bed temperature 447-454 ${ }^{\circ} \mathrm{C}$, HDO temperature: $364-386^{\circ} \mathrm{C}$, biomass feeding rate: $159-389 \mathrm{~g} / \mathrm{min}, \mathrm{H}_{2} \mathrm{~S}$ concentration: 47-475 ppm, $\mathrm{H}_{2}$ flow: 11.4-124.4 NL/min, $\mathrm{N}_{2}$ flow: 0.37-26.5 NL/min.

Based on the paraffins retention time on the 1D column it was possible to estimate the number of carbon 
As shown in Figure 6B the molecules were divided into 4 groups: less than 10 carbon atoms (-C10), between 11 and 15 carbon atoms (C11-C15), between 16 and 20 carbon atoms (C16-C20), and more than 20 carbon atoms $(\mathrm{C} 20+)$. The concentration of molecules with less than 10 carbon atoms increased from between 19 and $23 \%$ area-FID at 3.0 bar hydrogen to $49 \%$ area-FID at 8.2 bar, further increasing the hydrogen pressure to 35.8 bar increased the concentration to $52 \%$ area-FID. The reverse trend was observed for molecules with between 11 and 15 carbon atoms for which the concentration decreased from between 60 and $61 \%$ area-FID at 3.0 bar to $39 \%$ area-FID at 8.2 bar, and to $35 \%$ area-FID at 35.8 bar. This indicates that increasing the hydrogen pressure from 3.0 to 8.2 bar significantly increases the hydrocracking activity, while further increasing the hydrogen pressure has less effect on the hydrocracking activity. It should be noted that the concentration of molecules with between 16 and 20 carbon atoms was between 12 and $15 \%$ area-FID at 3.0 bar hydrogen and decreased to $9.9 \%$ area-FID at 35.8 bar hydrogen. This 385 area-FID at 35.8 bar hydrogen.

The chromatograms and composition of the organic phases from the experiments where the HDO reactor concentration of larger oxygenated aromatics to $0.1 \%$ area-FID and dihydroxybenzenes were not detected at this hydrogen pressure. Traces of sterols ( $0.1 \%$ area-FID) were also detected at 3.0 bar hydrogen, but 
more stable and less reactive than the organic phase produced at 3.0 bar hydrogen. It is therefore likely that the organic phase produced at 25.8 bar hydrogen can easily be co-feed into an existing refinery unit, 401 while co-feeding the organic phase produced at 3.0 bar will most likely lead to catalyst deactivation due to 402 the furans and multifunctional phenols present in the organic phase. Furthermore, the organic phase 403 produced at 3.0 bar is most likely less miscible with fossil oil due to its high oxygen content. However, it 404 should also be noted that dihydroxybenzenes were not detected in any of the experiments with the HDO 405 reactor, thus multifunctional phenols were only detected at 3.0 bar hydrogen when the HDO reactor was 406 bypassed. Furthermore, the molecular size distribution was also very different for produced organics when 407 the HDO reactor was bypassed. $32 \%$ area-FID of the molecules contains less than 10 carbon atoms at 3.0 408 bar hydrogen, while $41 \%$ contains less than 10 carbon atoms at 25.8 bar hydrogen, showing that 409 decreasing the hydrogen pressure leads to a heavier organic phase. 

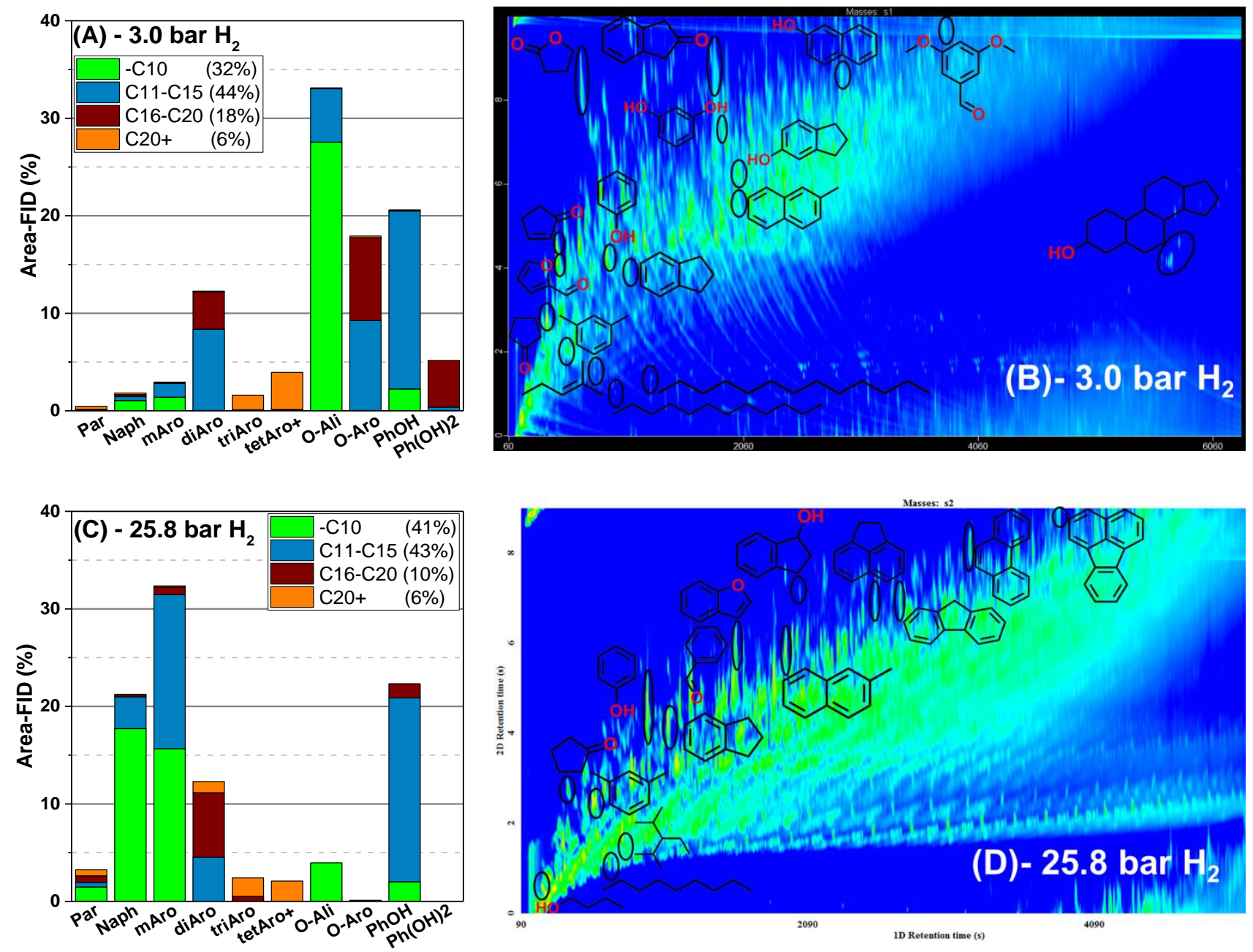

Figure 7 Composition of the organic phase when the HDO reactor is bypassed at 3.0 bar hydrogen (A,B) and at 25.8 bar hydrogen $(C, D)$. The components in the condensed organics are divided into paraffins (Par), naphthenes (Naph), monoaromatics (mAro), diaromatics (diAro), triaromatics (triAro), tetraaromatics and larger aromatics (tetAro+), oxygenated aliphatics (0-ali), phenols $(\mathrm{PhOH})$, dihydroxybenzenes $(\mathrm{Ph}(\mathrm{OH}) 2)$, and larger oxygenated aromatics (O-aro). Conditions: fluid bed temperature $450-454{ }^{\circ} \mathrm{C}$, biomass feeding rate: $174-350 \mathrm{~g} / \mathrm{min}, \mathrm{H}_{2} \mathrm{~S}$ concentration: $48-475 \mathrm{ppm}, \mathrm{H}_{2}$ flow: 11.4-87 NL/min, $\mathrm{N}_{2}$ flow: 0.62-26.5 NL/min.

\subsubsection{Sulfur specific GC-AED}

The sulfur content in the condensed organic phases was measured to be between 0.033 and $0.417 \mathrm{wt} . \% \mathrm{db}$ with energy dispersive X-ray fluorescence, which indicates an incorporation of sulfur into the produced organics. The sulfur content in the organic phase therefore needs to be reduced before it can be used as transportation fuel for cars. Since the reactivity of sulfur molecules is highly dependent on the type of molecules, for instance dibenzothiophene is very difficult to desulfurize [38], it is important to investigate the type of sulfur compounds in the organic phase. Therefore, 5 of the condensed organic phases were analyzed with sulfur specific GC-AED and the detected compounds were divided into thiols, thiophenes, benzothiophenes, other sulfur containing hydrocarbons such as DMDS and carbonylsulfide, and 
unidentified. Detailed lists of the detected compounds are shown in supplementary material Tables S.1 -

S.5. This showed that the samples contained between 17 and 232 wt-ppm S as $\mathrm{H}_{2} \mathrm{~S}$, which was not properly removed during the stripping. When the HDO reactor was bypassed at 3.0 bar hydrogen the concentration of thiols was 23 wt-ppm S, but between 0 and 3 wt-ppm S when the HDO reactor was used, see Figure 8 , showing that even at low hydrogen pressures the thiols were removed in the HDO reactor. The concentration of thiophenes was 220 wt-ppm S at 3.0 bar hydrogen without the HDO reactor, but 298 wtppm S at 3.0 bar hydrogen (10 bar total pressure) with HDO reactor, indicating that thiophenes are formed in the HDO reactor. However, it should be noted that the concentration of unidentified compounds was 96 wt-ppm S when the HDO reactor was bypassed and 34 wt-ppm S when the HDO reactor was used, thus it is likely that the organic phase from experiments without the HDO reactor contains some unidentified thiophenes or benzothiophenes.

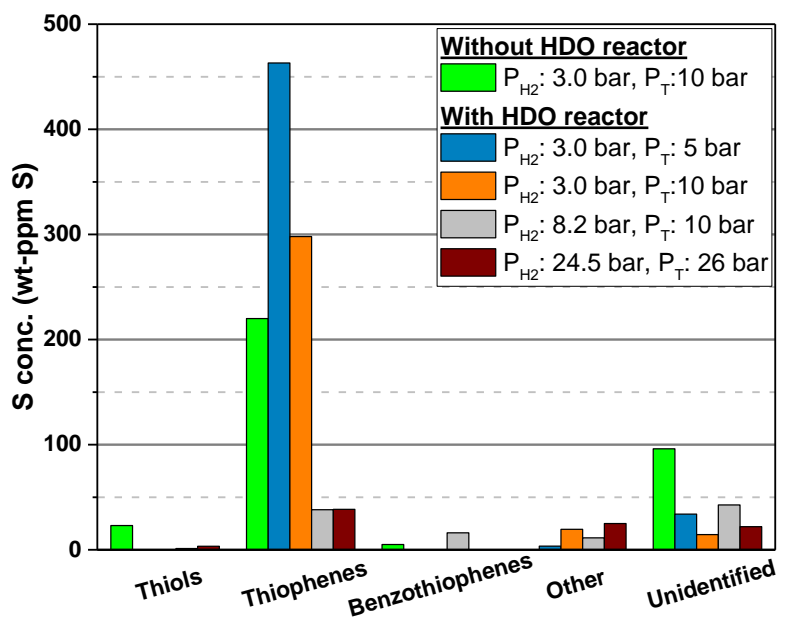

Figure 8 Effect of the hydrogen partial pressure and the total pressure on the concentration of organic sulfur species in the condensed organic phase. Conditions: fluid bed temperature $447-454{ }^{\circ} \mathrm{C}$, HDO temperature: $364-386{ }^{\circ} \mathrm{C}$, biomass feeding rate: 159-389 g/min, $\mathrm{H}_{2} \mathrm{~S}$ concentration: 47-475 ppm, $\mathrm{H}_{2}$ flow: 11.4-124.4 NL/min, $\mathrm{N}_{2}$ flow: 0.37-26.5 NL/min.

Interestingly, the concentration of thiophenes was 463 wt-ppm S when the total pressure was 5 bar (3.0 HDO reactor, indicating that the total pressure influences the thiophene concentration. The thiophene 
concentration of benzothiophenes was 16 wt-ppm S at 8.2 bar hydrogen, but was not detected at 24.5 bar

hydrogen. Furthermore, the total concentration of sulfur containing compounds was 109 wt-ppm S at 8.2 bar hydrogen and 84 wt-ppm S at 24.5 bar hydrogen. This therefore shows that the sulfur compounds in the produced organic phase are fairly similar to the sulfur compounds produced in fluid catalytic cracking [39] and does not contain the very stable dibenzothiophenes [38], thus the sulfur can relatively easily be removed in a modern refinery.

\subsubsection{Aqueous phase composition}

The carbon content in the aqueous phases was below $0.02 \mathrm{wt} . \%$ in the experiments where the HDO reactor was used and the hydrogen pressure was 15.9 bar or higher, see Table 1. Decreasing the hydrogen pressure to 8.2 bar increased the carbon content in the aqueous phase to $0.66 \mathrm{wt} . \%$ and further decreasing the hydrogen pressure to 3.0 bar increased the carbon content to between 0.70 and 0.81 wt.\%, depending on the total pressure. Furthermore, bypassing the HDO reactor at 3.0 bar hydrogen the carbon content in the aqueous phase was 12.3 wt.\%, while it was 1.3 wt.\% at 25.8 bar hydrogen. This shows that conducting catalytic hydropyrolysis at low hydrogen pressures ( $<15.8$ bar) even with a HDO reactor lead to higher carbon content in the aqueous phase, which could increase the operating expenses for waste water treatment.

In order to obtain a more thorough understanding of the oxygenates the aqueous phase, the aqueous phases with more than 0.02 wt.\% carbon were analyzed with GC-MS/FID. The detected oxygenates were divided into 8 groups: alcohols, furans, acids, ketones, phenols, sugars, esters, aldehydes and unidentified. Lists of the detected compounds can be found in supplementary material Tables S.6-S.10. To compare the concentrations in the different aqueous phases the relative FID area (the FID area of one group divided with total area) was multiplied with the concentration of carbon in the aqueous phase, as shown in Figure 9. When the HDO reactor was used most of the aqueous phase oxygenates were phenols and the phenol concentration increased from 0.11 to $0.31 \mathrm{wt} . \%$ when the hydrogen pressure was decreased from 8.2 to 3.0 bar (10 bar total pressure). At 8.2 bar hydrogen no acids were detected, but at 3.0 bar hydrogen (10 bar 
total pressure) acetic acid, propanoic acid, and butanoic acid were detected, corresponding to a total concentration of 0.009 wt.\%. Ketones were also observed at 3.0 bar hydrogen at both 5 and 10 bar total pressure, showing that at 3.0 bar hydrogen the rate of HDO is too low to convert even the more reactive oxygenates. However, the concentration of alcohols was below 0.1 wt.\% in all the experiments with the HDO reactor.

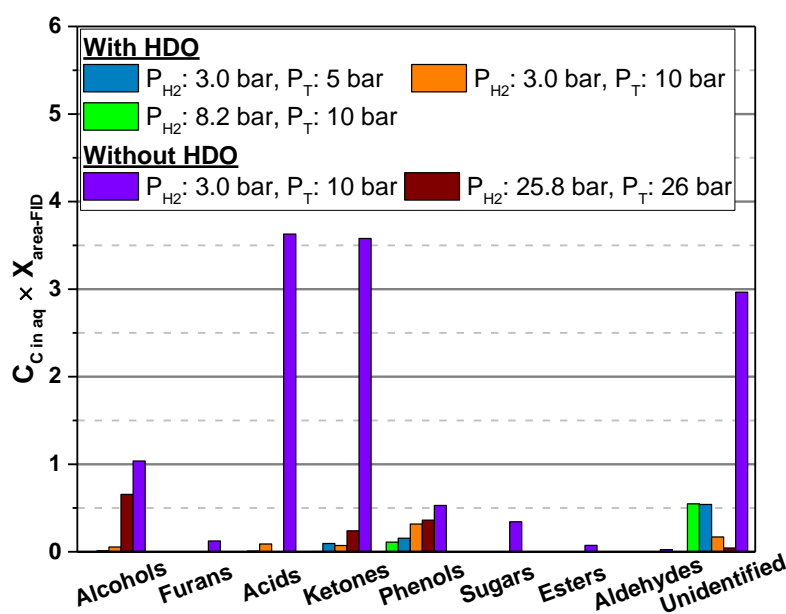

Figure 9 Effect of the hydrogen partial pressure and total pressure on composition of the aqueous phase. The concentration is calculated by multiplying the total concentration of the carbon in the aqueous phase with the fraction (area-FID) of the different compounds.

Bypassing the HDO reactor increased the concentration of alcohols to 1.0 wt.\% at 3.0 bar hydrogen and 0.66 wt.\% at 25.8 bar hydrogen. Likewise, the phenols concentration increased to 0.53 wt.\% at 3.0 bar hydrogen and 0.36 wt.\% at 25.8 bar hydrogen and the concentration of ketones increased to $3.6 \mathrm{wt} . \%$ at 3.0 bar hydrogen and 0.24 wt.\% at 25.8 bar hydrogen. At 3.0 bar hydrogen furans ( 0.12 wt.\%), sugars (0.34 wt.\%), esters (0.073 wt.\%), aldehydes (0.024 wt.\%) were also observed, none of these compounds were detected at 25.8 bar hydrogen, showing that the aqueous phase formed at 3.0 bar hydrogen contains much more reactive oxygenates than the aqueous phase formed at 25.8 bar.

\subsection{Characterization of the spent catalysts}

\subsubsection{Fluid bed reactor}

The carbon content on the spent catalysts from the fluid bed reactor was investigated with SEM-EDS and the acceleration voltage was varied between 3 and $15 \mathrm{kV}$. At $3 \mathrm{kV}$ the carbon concentration at the surface 
was measured and at $15 \mathrm{kV}$ a concentration closer to the bulk was measured, as described in detail in ref.

491

492

493

494

495

[36]. In order to account for the background carbon measurement, the carbon content on the catalysts was calculated by subtracting the measured carbon content on the fresh catalyst from the carbon on the spent catalysts (see supplementary material equation S.1). The measured carbon content on the catalysts is shown at different acceleration voltages in supplementary material Table S.11. Figure 10 shows the measured concentration of carbon at $15 \mathrm{kV}$ as a function of the hydrogen pressure. It can be seen that at hydrogen pressures between 15.9 and 35.8 bar the carbon concentration varied between 4.8 and 6.2 wt.\%, differences within the measurement uncertainty, and hence the coke formation was unaffected by the hydrogen pressure in this range. However, decreasing the hydrogen pressure to 8.2 bar increased the carbon concentration to $8.8 \mathrm{wt} . \%$ and further decreasing the hydrogen pressure to 3.0 increased the carbon content to between 12.2 and $20.7 \mathrm{wt} . \%$. Part of the reason for the large variation in the carbon content at 3.0 bar hydrogen is that different amounts of biomass were used. When $513 \mathrm{~g}$ daf biomass was used the carbon content was 12.2 wt.\%, while it was 16.0 wt.\% when $972 \mathrm{~g}$ daf was used and 20.7 wt.\% when $899 \mathrm{~g}$ daf was used. As shown in supplementary material Figure S.3 the carbon content on the catalysts, which had a bulk carbon content of 16.0 and $20.7 \mathrm{wt} . \%$ (measured at $15 \mathrm{kV}$ ), had a higher carbon concentration at surface (between 20.8 and $25.6 \mathrm{wt} . \%$ ). This indicates that carbon was building up on the surface of the catalyst, which over time could lead to blocking of the pores. The carbon content on the spent catalysts from the fluid bed reactor therefore indicates that at hydrogen pressures of 15.9 bar and above there is sufficient hydrogen for the catalyst to stabilize the reactive molecules before they can participate in polymerization reactions on the surface. These observations are therefore in alignment with the knowledge from hydrotreating of fossil oil, where it is well-known that high hydrogen pressure decreases the degree of coking due to stabilization of coke precursors [40]. 


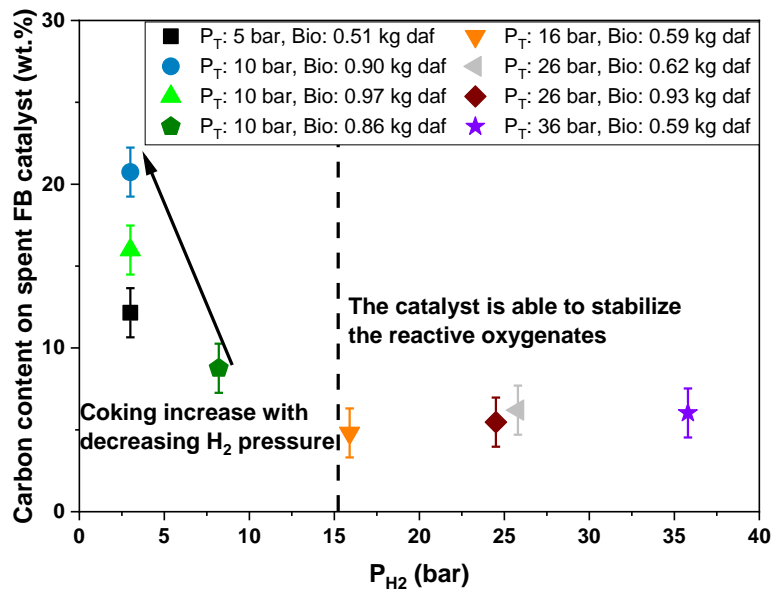

Figure 10 Carbon content on the spent catalysts from the fluid bed (FB) reactor, measured with SEM-EDS at $15 \mathrm{kV}$. Conditions: fluid bed temperature $447-454^{\circ} \mathrm{C}$, HDO temperature: $364-386{ }^{\circ} \mathrm{C}$, biomass feeding rate: $159-389 \mathrm{~g} / \mathrm{min}, \mathrm{H}_{2} \mathrm{~S}$ concentration: 47$475 \mathrm{ppm}, \mathrm{H}_{2}$ flow: 11.4-124.4 NL/min, $\mathrm{N}_{2}$ flow: 0.37-26.5 NL/min.

\subsubsection{HDO reactor}

517 The carbon content on the spent catalysts from the HDO reactor was also measured as shown in Figure 11.

518 The catalyst in the HDO reactor was not exchanged between experiments 1 to 4 , and had prior to 519 experiment 1 also been used in another experiment at 24.5 bar hydrogen. Despite that this catalyst had 520 been used for several experiments (at high hydrogen partial pressure), the carbon content was only 1.29 521 wt.\%, while it was 2.94 wt.\% on the catalyst that was tested at 8.2 bar hydrogen, 4.43 wt.\% on the catalyst tested at 3.0 bar hydrogen ( $0.51 \mathrm{~kg}$ daf biomass used), and $5.59 \mathrm{wt} . \%$ on the catalyst that was tested at 3.0 bar hydrogen ( $0.90 \mathrm{~kg}$ daf biomass used). This shows that the degree of coking of the catalyst in the HDO reactor increased with decreasing hydrogen partial pressure. The reason for this observation is most likely a combination of the low hydrogen pressure, the higher oxygen content in the hydrocarbons produced in the fluid bed reactor and the more reactive and multifunctional oxygenates, as discussed in the Section 3.2. 


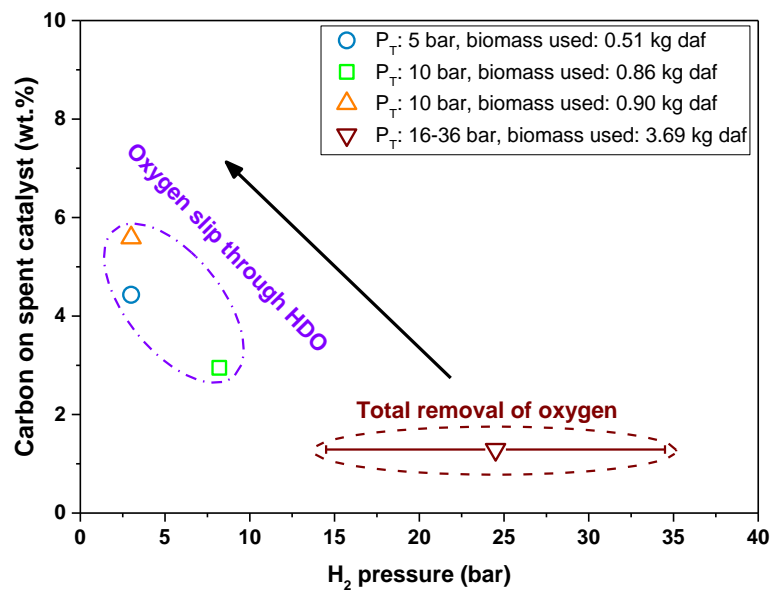

530 Figure 11 Carbon content on the spent catalyst from the HDO reactor. Conditions: fluid bed temperature 447-454 ${ }^{\circ} \mathrm{C}$, HDO 531 temperature: $364-386^{\circ} \mathrm{C}$, biomass feeding rate: $159-389 \mathrm{~g} / \mathrm{min}, \mathrm{H}_{2} \mathrm{~S}$ concentration: $47-475 \mathrm{ppm}, \mathrm{H}_{2}$ flow: 11.4-124.4 NL/min, $\mathrm{N}_{2}$ 532 flow: $0.37-26.5 \mathrm{NL} / \mathrm{min}$.

\section{Conclusion}

534 Catalytic hydropyrolysis of beech wood was conducted in a fluid bed reactor followed by a fixed bed HDO 535 reactor, at a total pressure between 5 and 36 bar and a hydrogen pressure between 3.0 and 35.8 bar. At 536 hydrogen pressures below 15.9 bar the solid yield increased from $11.0 \mathrm{wt} . \%$ daf at 15.9 bar hydrogen to $537 \quad 15.7$ wt.\% daf at 3.0 bar hydrogen, showing that at low hydrogen pressures the pyrolysis vapors are not 538 sufficiently stabilized, leading to polymerization. The organic phase produced at between 15.9 and 35.8 bar 539 hydrogen pressure was essentially oxygen free $(<0.01 \mathrm{wt} . \%)$, but the oxygen content increased with 540 decreasing pressure and an oxygen content up to $7.8 \mathrm{wt} . \% \mathrm{db}$ was measured at 3.0 bar hydrogen, where 541 the oxygenates were mainly phenols. In addition conducting the experiments at 3.0 and 25.8 bar hydrogen pressure without the HDO reactor, showed that the oxygenates in the condensed liquid phases at 25.8 bar hydrogen mainly consisted of phenols, while the oxygenates from the experiment conducted at 3.0 bar consisted of phenols, dihydroxybenzenes, larger aromatics, and a high concentration of oxygenated 545 aliphatics.

The carbon content on the spent catalysts from both the fluid bed and HDO reactor was measured. Varying the hydrogen partial pressure between 15.9 and 35.8 bar did not have an impact on the carbon content on 
the spent catalyst from the fluid bed, however further decreasing the hydrogen pressure increased the carbon content, indicating an increased deactivation of the catalyst. Similarly, a higher carbon content was observed on the spent catalyst from the HDO reactor when operating at below 15.9 bar hydrogen pressure.

The higher carbon on the catalysts from experiments at low hydrogen pressures ( 15.9 bar) is because the oxygenates produced at low hydrogen pressures are more reactive, thus increasing the rate of coking. The results show, that despite being easier to feed biomass at low pressure, it may lead to a more reactive product, which can decrease the catalyst life time and may limit further processing in a refinery.

\section{Acknowledgments}

This work is part of the project "Hydrogen assisted catalytic pyrolysis for green fuels" conducted at The Department of Chemical and Biochemical Engineering at the Technical University of Denmark (DTU). The work was supported by The Danish Council for Strategic Research (now Innovation Fund Denmark, project 1305-00015B), The Programme Commission on Sustainable Energy and Environment. Funding from DTU is also gratefully acknowledged. The authors acknowledge the Organic Analysis Department at Haldor Topsøe $\mathrm{A} / \mathrm{S}$ for analysis of the organic phase and the Inorganic Analysis Department at Haldor Topsøe $A / S$ for carbon on the spent catalysts.

\section{References}

[1] T.L. Marker, L.G. Felix, M.B. Linck, M.J. Roberts, Integrated hydropyrolysis and hydroconversion $\left(\mathrm{IH}^{2}\right)$ for the direct production of gasoline and diesel fuels or blending components from biomass, Part 1: Proof of principle testing, Environ. Prog. Sustain. Energy. 31 (2012) 191-199. doi:10.1002/ep.10629.

[2] T.L. Marker, L.G. Felix, M.B. Linck, M.J. Roberts, P. Ortiz-Toral, J. Wangerow, Integrated hydropyrolysis and hydroconversion $\left(\mathrm{IH}^{2^{\circ}}\right)$ for the direct production of gasoline and diesel fuels or blending components from biomass, Part 2: Continuous testing, Environ. Prog. Sustain. Energy. 33 
571 [3] E. Maleche, R. Glaser, T. Marker, D. Shonnard, A preliminary life cycle assessment of biofuels

[4] J. Fan, J. Gephart, T. Marker, D. Stover, B. Updike, D.R. Shonnard, Carbon Footprint Analysis of

[5] T.M.H. Dabros, M.Z. Stummann, M. Høj, P.A. Jensen, J.-D. Grunwaldt, J. Gabrielsen, P.M. Mortensen,

[6] D.C. Dayton, J. Carpenter, J. Farmer, B. Turk, R. Gupta, Biomass hydropyrolysis in a pressurized

[8] D.C. Dayton, J. Hlebak, J.R. Carpenter, K. Wang, O.D. Mante, J.E. Peters, Biomass hydropyrolysis in a 586

[7] K. Wang, D.C. Dayton, J.E. Peters, O.D. Mante, Reactive catalytic fast pyrolysis of biomass to produce high-quality bio-crude, Green Chem. 19 (2017) 3243-3251. doi:10.1039/C7GC01088E. fluidized bed reactor, Energy \& Fuels. 30 (2016) 4879-4887. doi:10.1021/acs.energyfuels.6b00373.

[9] S. Thangalazhy-Gopakumar, S. Adhikari, R.B. Gupta, M. Tu, S. Taylor, Production of hydrocarbon fuels from biomass using catalytic pyrolysis under helium and hydrogen environments., Bioresour. Technol. 102 (2011) 6742-9. doi:10.1016/j.biortech.2011.03.104.

[10] S. Thangalazhy-Gopakumar, S. Adhikari, R.B. Gupta, Catalytic pyrolysis of biomass over $\mathrm{H}^{+} \mathrm{ZSM}-5$ under hydrogen pressure, Energy \& Fuels. 26 (2012) 5300-5306. doi:10.1021/ef3008213. 
[11] O. Jan, R. Marchand, L.C.A. Anjos, G.V.S. Seufitelli, E. Nikolla, F.L.P. Resende, Hydropyrolysis of lignin using Pd/HZSM-5, Energy \& Fuels. 29 (2015) 1793-1800. doi:10.1021/ef502779s.

[12] F. Melligan, M.H.B. Hayes, W. Kwapinski, J.J. Leahy, Hydro-pyrolysis of biomass and online catalytic vapor upgrading with Ni-ZSM-5 and Ni-MCM-41, Energy \& Fuels. 26 (2012) 6080-6090. doi:10.1021/ef301244h.

[13] P. Choudhary, A. Malik, K.K. Pant, Mass-Scale Algal Biomass Production Using Algal Biofilm Reactor and Conversion to Energy and Chemical Precursors by Hydropyrolysis, ACS Sustain. Chem. Eng. 5 (2017) 4234-4242. doi:10.1021/acssuschemeng.7b00233.

[14] R.. Pindoria, A. Megaritis, A.. Herod, R. Kandiyoti, A two-stage fixed-bed reactor for direct hydrotreatment of volatiles from the hydropyrolysis of biomass: effect of catalyst temperature, pressure and catalyst ageing time on product characteristics, Fuel. 77 (1998) 1715-1726. doi:10.1016/S0016-2361(98)00079-9.

[15] F. Melligan, M.H.B. Hayes, W. Kwapinski, J.J. Leahy, A study of hydrogen pressure during hydropyrolysis of Miscanthus $x$ giganteus and online catalytic vapour upgrading with Ni on ZSM-5, J. Anal. Appl. Pyrolysis. 103 (2013) 369-377. doi:10.1016/j.jaap.2013.01.005.

[16] V.K. Venkatakrishnan, J.C. Degenstein, A.D. Smeltz, W.N. Delgass, R. Agrawal, F.H. Ribeiro, Highpressure fast-pyrolysis, fast-hydropyrolysis and catalytic hydrodeoxygenation of cellulose: Production of liquid fuel from biomass, Green Chem. 16 (2014) 792-802. doi:10.1039/c3gc41558a.

[17] V.K. Venkatakrishnan, W.N. Delgass, F.H. Ribeiro, R. Agrawal, Oxygen removal from intact biomass to produce liquid fuel range hydrocarbons via fast-hydropyrolysis and vapor-phase catalytic hydrodeoxygenation, Green Chem. 17 (2015) 178-183. doi:10.1039/c4gc01746c.

[18] L. Zhang, K. Gong, J. Lai, P. Alvey, Chemical composition and stability of renewable hydrocarbon 
products generated from a hydropyrolysis vapor upgrading process, Green Chem. 19 (2017) 36283641. doi:10.1039/c7gc01075c.

[19] J. Lai, L. Zhang, K. Gong, Nuclear magnetic resonance characterization of renewable products from a two-step ex-situ hydropyrolysis vapor upgrading process, ChemistrySelect. 3 (2018) 297-307. doi:10.1002/slct.201702431.

[20] M.Z. Stummann, M. Høj, C.B. Schandel, A.B. Hansen, P. Wiwel, J. Gabrielsen, P.A. Jensen, A.D. Jensen, Hydrogen assisted catalytic biomass pyrolysis. Effect of temperature and pressure, Biomass and Bioenergy. 115 (2018) 97-107. doi:10.1016/j.biombioe.2018.04.012.

[21] O.I. Şenol, E.-M. Ryymin, T.-R. Viljava, A.O.I. Krause, Reactions of methyl heptanoate hydrodeoxygenation on sulphided catalysts, J. Mol. Catal. A Chem. 268 (2007) 1-8. doi:10.1016/j.molcata.2006.12.006.

[22] O.I. Şenol, T.-R. Viljava, A.O.I. Krause, Hydrodeoxygenation of aliphatic esters on sulphided NiMo/Y$\mathrm{Al}_{2} \mathrm{O}_{3}$ and $\mathrm{CoMo} / \mathrm{Y}-\mathrm{Al} 2 \mathrm{O} 3$ catalyst: The effect of water, Catal. Today. 106 (2005) 186-189. doi:10.1016/j.cattod.2005.07.129.

[23] O.i. Şenol, T.-R. Viljava, A.O.I. Krause, Effect of sulphiding agents on the hydrodeoxygenation of aliphatic esters on sulphided catalysts, Appl. Catal. A Gen. 326 (2007) 236-244. doi:10.1016/j.apcata.2007.04.022.

[24] E.-M. Ryymin, M.L. Honkela, T.-R. Viljava, A.O.I. Krause, Competitive reactions and mechanisms in the simultaneous $\mathrm{HDO}$ of phenol and methyl heptanoate over sulphided $\mathrm{NiMo} / \mathrm{\gamma}-\mathrm{Al}_{2} \mathrm{O}_{3}, \mathrm{Appl}$. Catal. A Gen. 389 (2010) 114-121. doi:10.1016/j.apcata.2010.09.010.

[25] A. Gutierrez, E.-M. Turpeinen, T.-R. Viljava, O. Krause, Hydrodeoxygenation of model compounds on sulfided $\mathrm{CoMo} / \mathrm{\gamma}-\mathrm{Al} 2 \mathrm{O} 3$ and $\mathrm{NiMo} / \mathrm{\gamma}-\mathrm{Al} 2 \mathrm{O} 3$ catalysts; Role of sulfur-containing groups in reaction 
networks, Catal. Today. 285 (2017) 125-134. doi:10.1016/j.cattod.2017.02.003.

[26] T.M.H. Dabros, A. Gaur, D.G. Pintos, P. Sprenger, M. Høj, T.W. Hansen, F. Studt, J. Gabrielsen, J.-D. Grunwaldt, A.D. Jensen, Influence of $\mathrm{H} 2 \mathrm{O}$ and $\mathrm{H} 2 \mathrm{~S}$ on the composition, activity, and stability of sulfided Mo, CoMo, and NiMo supported on MgAl2O4 for hydrodeoxygenation of ethylene glycol, Appl. Catal. A Gen. 551 (2018) 106-121. doi:10.1016/j.apcata.2017.12.008.

[27] V.N. Bui, D. Laurenti, P. Afanasiev, C. Geantet, Hydrodeoxygenation of guaiacol with CoMo catalysts. Part I: Promoting effect of cobalt on HDO selectivity and activity, Appl. Catal. B Environ. 101 (2011) 239-245. doi:10.1016/j.apcatb.2010.10.025.

[28] A. Centeno, E. Laurent, B. Delmon, Influence of the support of CoMo sulfide catalysts and of the addition of potassium and platinum on the catalytic performances for the hydrodeoxygenation of carbonyl, carboxyl, and guaiacol-type molecules, J. Catal. 154 (1995) 288-298. doi:10.1006/jcat.1995.1170.

[29] M. Badawi, J.-F. Paul, S. Cristol, E. Payen, Guaiacol derivatives and inhibiting species adsorption over $\mathrm{MoS}_{2}$ and CoMoS catalysts under HDO conditions: A DFT study, Catal. Commun. 12 (2011) 901-905. doi:10.1016/j.catcom.2011.02.010.

[30] T.M.H. Dabros, H. Kramer, M. Høj, P. Sprenger, J.-D. Grunwaldt, J. Gabrielsen, A.D. Jensen, The Influence of Active Phase Loading on the Hydrodeoxygenation (HDO) of Ethylene Glycol over Promoted MoS2/MgAl2O4 Catalysts, Top. Catal. (2019). doi:10.1007/s11244-019-01169-y.

[31] C. Bouvier, Y. Romero, F. Richard, S. Brunet, Effect of $\mathrm{H}_{2} \mathrm{~S}$ and $\mathrm{CO}$ on the transformation of 2ethylphenol as a model compound of bio-crude over sulfided Mo-based catalysts: propositions of promoted active sites for deoxygenation pathways based on an experimental study, Green Chem. 13 (2011) 2441-2451. doi:10.1039/c1gc15181a. 


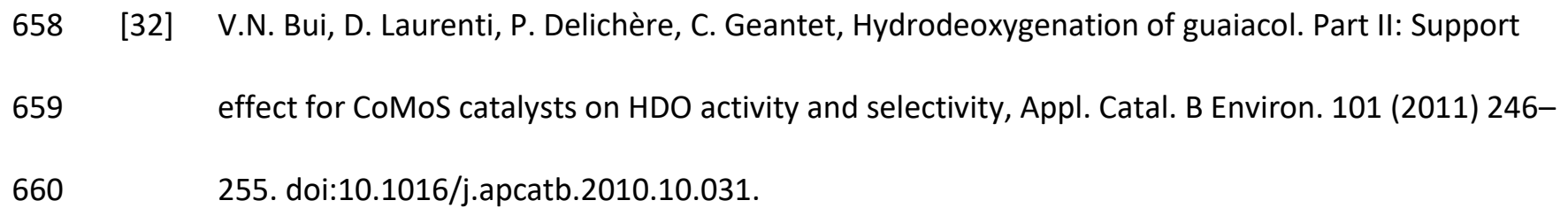

661 [33] V.O.O. Gonçalves, S. Brunet, F. Richard, Hydrodeoxygenation of cresols over $\mathrm{Mo} / \mathrm{Al}_{2} \mathrm{O}_{3}$ and 662 663 664 665

[35] M.Z. Stummann, A.B. Hansen, L.P. Hansen, B. Davidsen, S.B. Rasmussen, P. Wiwel, J. Gabrielsen, P.A.

[36] M.Z. Stummann, M. Høj, B. Davidsen, A.B. Hansen, L.P. Hansen, P. Wiwel, C.B. Schandel, J.

[34] E. Schachtl, J.S. Yoo, O.Y. Gutiérrez, F. Studt, J.A. Lercher, Impact of Ni promotion on the hydrogenation pathways of phenanthrene on $\mathrm{MoS}_{2} / \mathrm{Y}-\mathrm{Al}_{2} \mathrm{O}_{3}$, J. Catal. 352 (2017) 171-181. doi:10.1016/j.jcat.2017.05.003. Jensen, A.D. Jensen, M. Høj, Catalytic Hydropyrolysis of Biomass Using Molybdenum Sulfide Based Catalyst. Effect of Promoters, Energy \& Fuels. 33 (2019) 1302-1313. doi:10.1021/acs.energyfuels.8b04191. Gabrielsen, P.A. Jensen, A.D. Jensen, Effect of the catalyst in fluid bed catalytic hydropyrolysis, Catal. Today. (2019). doi:10.1016/j.cattod.2019.01.047.

[37] T.M.H. Dabros, A Step in Understanding and Optimizing Fuel Production from Solid Biomass PhD Thesis, Technical University of Denmark, Dept. of Chemical and Biochemical Engineering, 2017.

[38] A. Stanislaus, A. Marafi, M.S. Rana, Recent advances in the science and technology of ultra low sulfur diesel (ULSD) production, Catal. Today. 153 (2010) 1-68. doi:10.1016/j.cattod.2010.05.011.

[39] A. Corma, C. Martínez, G. Ketley, G. Blair, On the mechanism of sulfur removal during catalytic cracking, Appl. Catal. A Gen. 208 (2001) 135-152. doi:10.1016/S0926-860X(00)00693-1. 
680 [40] E. Furimsky, F.E. Massoth, Deactivation of hydroprocessing catalysts, Catal. Today. 52 (1999) 381681 495. doi:10.1016/S0920-5861(99)00096-6.

682 